\title{
Heterostructures Based on 2D Materials: A Versatile Platform for Efficient Catalysis
}

\author{
Tofik Ahmed Shifa, Fengmei Wang, Yang Liu, and Jun He*
}

The unique structural and electronic properties of 2D materials, including the metal and metal-free ones, have prompted intense exploration in the search for new catalysts. The construction of different heterostructures based on 2D materials offers great opportunities for boosting the catalytic activity in electo(photo) chemical reactions. Particularly, the merits resulting from the synergism of the constituent components and the fascinating properties at the interface are tremendously interesting. This scenario has now become the state-of-the-art point in the development of active catalysts for assisting energy conversion reactions including water splitting and $\mathrm{CO}_{2}$ reduction. Here, starting from the theoretical background of the fundamental concepts, the progressive developments in the design and applications of heterostructures based on 2D materials are traced. Furthermore, a personal perspective on the exploration of 2D heterostructures for further potential application in catalysis is offered.

\section{Introduction}

Apart from size effect, dimensionality is also considered as an indispensable parameter in exploring the properties of materials. ${ }^{[1]}$ For instance, allotropes of carbon such as graphite, graphene, carbon nanotube, and fullerene appear as 3D, 2D, $1 \mathrm{D}$, and $0 \mathrm{D}$, respectively, and demonstrate distinct physical and chemical properties. The discovery of graphene in 2004 by Geim and co-workers ${ }^{[2]}$ has offered an opportunity to investigate various points in scientific research and engineering fields based on other 2D materials. ${ }^{[3]}$ Particularly to the context of catalysis, the design of $2 \mathrm{D}$ catalysts paves a promising way for excellent performance in activity, stability, and selectivity toward catalyzing a given reaction. Experimental and theoretical researches conducted so far reveal the fact that ultrathin 2D materials possess fascinating advantages in catalysis. ${ }^{[4-7]}$ First and for most, 2D geometry renders the materials considerably exposed surface area, which is more pronounced by reducing the thickness, eventually easing the contact between catalyst

Dr. T. A. Shifa, Dr. F. M. Wang, Y. Liu, Prof. J. He

CAS Center for Excellence in Nanoscience

CAS Key Laboratory of Nanosystem and Hierarchical Fabrication

National Center for Nanoscience and Technology

Beijing 100190, China

E-mail: hej@nanoctr.cn

Y. Liu, Prof. J. He

University of Chinese Academy of Sciences

Beijing 100049, P. R. China

The ORCID identification number(s) for the author(s) of this article can be found under https://doi.org/10.1002/adma.201804828.

DOI: 10.1002/adma.201804828 surface and the adsorbate. Moreover, the interior atoms could be brought to surface when the thickness is decreased to monolayer. Thus, more active sites would be availed for catalysis. To be noted, there is also a great possibility of introducing defects, unsaturated sites, and/or active edges during the formation of ultrathin structures. Under these conditions, the adsorption-desorption energy barrier is sequentially regulated and ion mobility or mass transport is facilitated. Furthermore, some materials beyond graphene, e.g., layered double hydroxides (LDH), possess improved electronic conductivity at ultrathin features as in the case of atomic-thickness nanosheets. ${ }^{[8]}$ And the exploration of nanometer thick 2D crystals with intriguing physical and chemical properties has effectively expanded the family of 2D materials. ${ }^{[9,10]}$

Notably, the unique structural and electronic properties of 2D materials have prompted intense exploration in search for catalysis. ${ }^{[4]}$ The successful preparation of various $2 \mathrm{D}$ crystals ${ }^{[11]}$ has nurtured the diversity of heterostructures that could be derived, where the synergetic effect plays a pivotal role in optimizing the kinetics and energetics of surface catalysis. ${ }^{[6,12]}$ Aiming at improving performance, frontiers of $2 \mathrm{D}$ materials such as graphene, graphitic carbon nitride $\left(\mathrm{g}-\mathrm{C}_{3} \mathrm{~N}_{4}\right)$, transition metal dichalcogenides (TMDs) have been integrated with other materials. The merits resulting from synergism of the constituent components and the fascinating properties at the interface are tremendously interesting. ${ }^{[6,13]}$ This scenario has now become the state-of-the-art point in the development of active catalysts for assisting energy conversion reactions including water splitting and $\mathrm{CO}_{2}$ reduction. Hence, the construction of heterostructures has gone through considerable advances deserving a comprehensive outlook and plausible forecasts. Herein, after introducing frontier 2D materials, we trace the progressive developments in the design and applications of their heterostructures. Particular emphasis will be given to the efforts for developing efficient catalysts to drive important, yet thermodynamically challenging, reactions. Finally, we offer our perspective on the exploration of 2D heterostructures for further potential application in catalysis.

\subsection{Graphene}

Graphene is characterized by a single-atom-thick nanosheet of planar structure (Figure 1a) in which $\mathrm{sp}^{2}$-hybridized carbon atoms are arranged in a honeycomb lattice imparting excellent 
conductivity and extraordinary mechanical and chemical stability. ${ }^{[14]}$ In the case where a heterostructure photocatalyst is designed making graphene as one of the components, a rapid electron transfer from the catalyst to graphene can be achieved as the Fermi level of graphene ( $0 \mathrm{~V}$ vs NHE) is lower than the conduction band position of most photocatalysts. This ensures a high spatial separation of the photogenerated electron-hole pairs due to the rapidly transferring of electrons from photocatalyst, whereas those of holes left for oxidation purpose, to grapheme. The ultralarge theoretical surface area $\left(2630 \mathrm{~m}^{2} \mathrm{~g}^{-1}\right)^{[15]}$ of graphene is also another feature. This can be associated with the increase of surface active sites which is quite beneficial for catalysis. ${ }^{[16]}$ The case of $\mathrm{CO}_{2}$ reduction takes particular advantages from the graphene's large 2D $\pi$-conjugated structure, well consistent with the $\pi$-conjugated bond in $\mathrm{CO}_{2}$ molecular. The initiation of a $\pi-\pi$ conjugation interaction between graphene and $\mathrm{CO}_{2}$ remarkably contributes to the adsorption of $\mathrm{CO}_{2}$ moleculars on the surface of graphene containing catalysts and eventually easing their reduction. ${ }^{[17]}$ Another intriguing feature that currently won the attention is the possibility of atomic dispersion in the graphene matrix. ${ }^{18-20]}$ This is practically obvious for reduced graphene oxide (rGO) that develops a large volume of surface functional groups that would serve as anchoring sites and prevent aggregation. ${ }^{[21]}$ Thus, various metal atoms, e.g., $\mathrm{Ni}^{[22]} \mathrm{Co}^{[23]}$ etc., can be uniformly deposited on the surface of graphene or rGO nanosheets with atomic dispersion. The single-atom implantation on the 2D surface could realize excellent catalytic activity in $\mathrm{CO}_{2}$ reduction and hydrogen evolution reaction (HER). This conveys the current status of this field that has now reached the level of tenaciously implanting single metal atom in 2D materials for superior activity.

\subsection{Graphitic Carbon Nitride}

The metal-free polymeric material known as g- $\mathrm{C}_{3} \mathrm{~N}_{4}$ is perhaps one of the oldest 2D framework in the record of scientific literatures. Its history goes back to the identification of melon, linear polymer consisting of interconnected tri-s-triazines via secondary nitrogen, in the 1830 s (Figure 1b). ${ }^{[24]}$ In the case of $\mathrm{g}-\mathrm{C}_{3} \mathrm{~N}_{4}$, the arrangement appears in the 2D form in which the atoms are composed of tri-s-triazines interconnected via tertiary amines. There exists a close resemblance in terms of $\pi$-conjugation and 2D feature with that of graphite as has been proven experimentally. ${ }^{[25]}$ The altered localization of electrons and the presence of nitrogen atoms are thought to be the reason behind the smaller interlayer distance $(0.326 \mathrm{~nm})$ in $\mathrm{g}-\mathrm{C}_{3} \mathrm{~N}_{4}$ than that in graphite $(0.335 \mathrm{~nm}) \cdot{ }^{[26]}$ The most intriguing feature of $\mathrm{g}_{-} \mathrm{C}_{3} \mathrm{~N}_{4}$ relies on the s-triazine ring structure. It shows a considerable thermal (up to $600{ }^{\circ} \mathrm{C}$ in air) and chemical resistance (stable in acids, alkalis, and various organic solvents). Unlike graphene, g- $\mathrm{C}_{3} \mathrm{~N}_{4}$ possesses an appealing electronic structure with suitable bandgap for harvesting solar energy in a wider spectrum. ${ }^{[26,27]}$ The history of $2 \mathrm{D}$ g- $\mathrm{C}_{3} \mathrm{~N}_{4}$ in heterogeneous catalysis is rather very recent. It has been recognized as a metal-free visible-light-driven photocatalyst for hydrogen production from water in 2009.[27] This material is significantly robust and nonvolatile because its oxidation and reduction

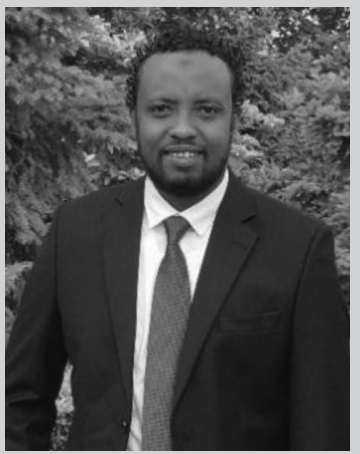

Tofik Ahmed Shifa obtained his B.Sc. degree in applied chemistry from Arbaminch University, Ethiopia in 2007. He then obtained M.Sc. degree in analytical chemistry from Haramaya University, Ethiopia in 2011. After working as a lecturer at Haramaya University for 2 years, he was admitted at the University of Chinese Academy of Sciences, National Center for Nanoscience and Technology (NCNST) where he received a Ph.D. degree in physical chemistry in June 2018. His research focuses on the controllable synthesis of 2D layered materials for water splitting.

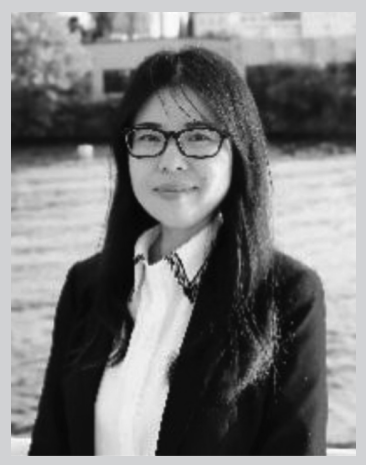

Fengmei Wang received her B.Sc. degree in applied chemistry from Hunan University, China, in 2012. Then, she received her Ph.D. degree in physical chemistry from University of Chinese Academy of Sciences at National Center for Nanoscience and Technology (NCNST), China, in 2017. From then on, she worked in NCNST as an assistant professor. Her major research interests include synthesis and development of novel 2D materials, such as transition metal chalcogenides, metal phosphorous trichalcogenides, etc., for electrocatalysis or photocatalysis.

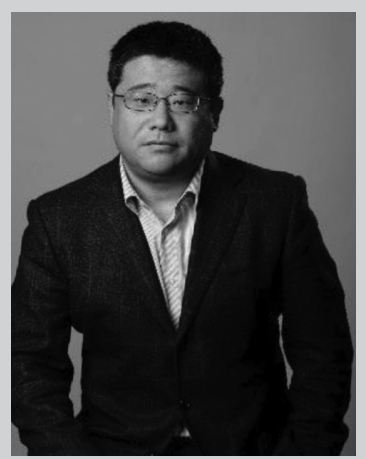

Jun He received his Ph.D. degree in semiconductor physics from the Institute of Semiconductors, Chinese Academy of Sciences (CAS), in 2003. Then, he worked successively at Applied Physics Department of Technische Universiteit Eindhoven, Netherlands, Material Department of University of California, Santa Babara, and California NanoSystem Institute (CNSI), University of California, Los Angeles, USA. He joined the "100-Talents" Program of CAS in November 2010 and became a Full Professor of National Center for Nanoscience and Technology (NCNST) since then. His main research interests are the synthesis, characterization, and devices of low-dimensional semiconductor materials.

potentials are energetically suitable for water splitting. It is also possible to entrap metal or other functional materials to expose active sites with abundant melon moieties in the framework. It 
(a)

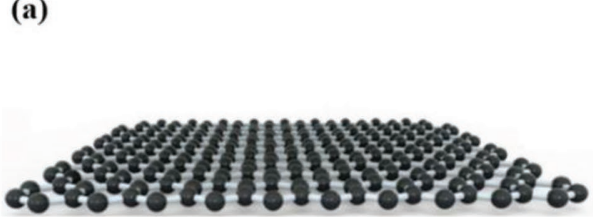

\section{Graphene}

(d)

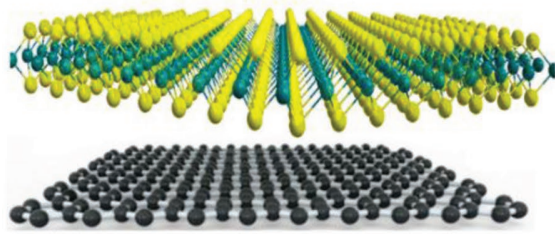

2D-2D (b)

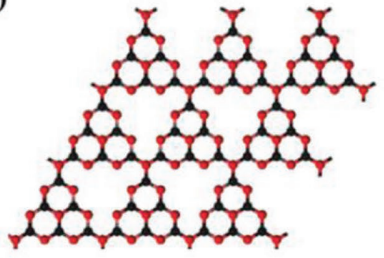

Graphitic carbon nitride $\left(\mathrm{g}-\mathrm{C}_{3} \mathrm{~N}_{4}\right)$

(e)

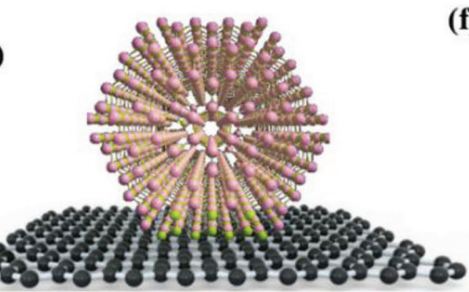

1D-2D (c)

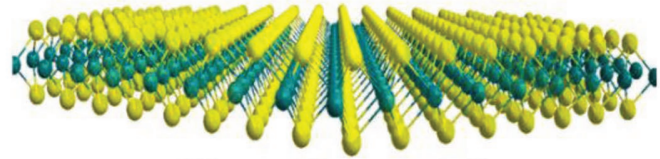

Transition metal dichalcogenides $\left(\mathbf{M X}_{2}\right)$

(f)

Figure 1. Frontiers of $2 \mathrm{D}$ materials used in catalysis and their heterostructures: a) graphene, b) $\mathrm{g}-\mathrm{C}_{3} \mathrm{~N}_{4}$, c) transition metal dichalcogenides, d) 2D-2D, e) 1D-2D, and f) 0D-2D.

is predictable that combining g- $\mathrm{C}_{3} \mathrm{~N}_{4}$ with other $2 \mathrm{D}$ materials, e.g., $\mathrm{MoS}_{2},{ }^{[28]} \mathrm{NiFe}-\mathrm{LDH},{ }^{[29]}$ etc., will induce unique electronic, mechanical, and chemical properties tunable with respect to efficiently catalyzing the desired reaction. This results in a tremendous amount of interest to construct active and stable catalysts.

\subsection{Transition Metal Dichalcogenides}

Transition metal dichalcogenides are other class of 2D materials that are vastly investigated following the unconventional properties of graphene. ${ }^{[30,31]}$ TMDs have attracted significant interests due to their promising energy applications and striking fundamental properties. The typical crystal structure is illustrated in Figure 1c. In their layered structure, each unit is composed of a transition metal (M) layer sandwiched between two chalcogen $(\mathrm{X})$ atomic layers. Depending on the particular combination of transition metal and chalcogen elements, TMDs can have thermodynamically stable phase of either $2 \mathrm{H}$ or $1 \mathrm{~T}$ phase, and other phases can be obtained as a metastable. The atoms are covalently bonded within each layer $(\mathrm{X}-\mathrm{M}-\mathrm{X})$, where the metal and chalcogen atoms have oxidation states of +4 and -2 , respectively. And the individual layers are connected together by weak van der Waals (vdW) forces. ${ }^{[31]}$ The surface of the layers is terminated by the lone pair of chalcogen atoms. As a result of the difference in oxidation states, considerable ionic character is induced between the metal and chalcogen atoms. ${ }^{[31]}$ Moreover, the 2D TMD nanosheets could be achieved by exfoliation of bulk crystals or building up individual atoms via vapor deposition. ${ }^{[32]}$ These situations pave the way leading to maximal exposure of active sites for catalysis. The unique structure of TMDs can also be visualized from the perspectives of two distinctive orientation featured by surface inertness (basal planes) and high surface energy (edges) exhibiting anisotropic properties. It has been observed ${ }^{[33]}$ that the electrical conductivity along the layer is $\approx 2200$ times higher than that across the vdW gaps between layers, predicting a considerably faster electron transport on the edges as compared to the basal planes. Such inherent characteristic of TMDs can give rise to a prominently active catalysis in electrocatalytic hydrogen evolution reaction provided that the active edges is maximally exposed. [34] Therefore, increasing the conductivity and improving the density of accessible edges of TMDs have been proposed in the past few years as a means of attaining enhanced performances. Heterostructurring plays a pivotal role in tuning the catalytic activities of TMDs.

\subsection{Others}

Many other 2D layered materials, such as transition metal carbonitrides (MXenes), ${ }^{[35]}$ layered double hydroxides, ${ }^{[36]}$ metal-organic frameworks (MOFs), ${ }^{[37]}$ etc., are designed and synthesized. These basic crystal structure are used as catalysts for given reactions. As to MXenes, they are widely utilized as active materials in energy conversion. ${ }^{[38]}$ Some of them are explored for catalyzing water splitting. For example, $\mathrm{Mo}_{2} \mathrm{CT}_{x}$ was theoretically and experimentally studied by She et al. ${ }^{[39]}$ for stable HER activity in acid media. It possessed a small hydrogen absorption energy of $0.048 \mathrm{eV}$. They speculated that the basal planes of $\mathrm{Mo}_{2} \mathrm{CT}_{x}$ are catalytically active toward HER, which is different with the case in hexagonal phased $\mathrm{MoS}_{2}$.

\section{Heterostructures Based on 2D materials}

This extensive library of layered 2D materials provides the possibility to design heterogeneous integration for novel hybrid structures. The dangling-bond-free surface is demonstrated 
(a)

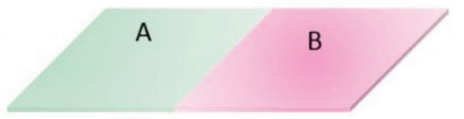

(b)

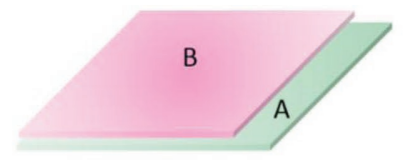

(c)

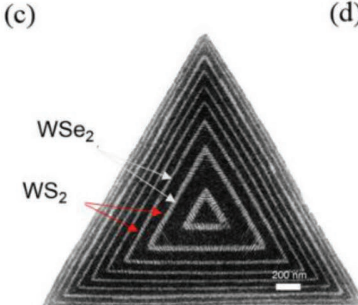

(e)

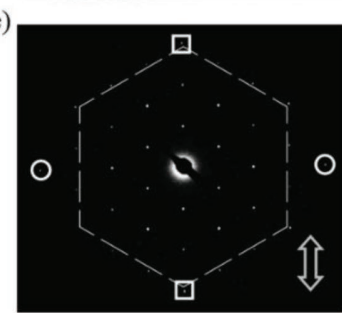

(d)
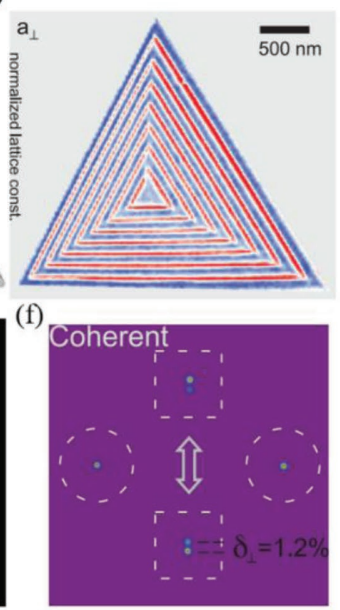

(g)
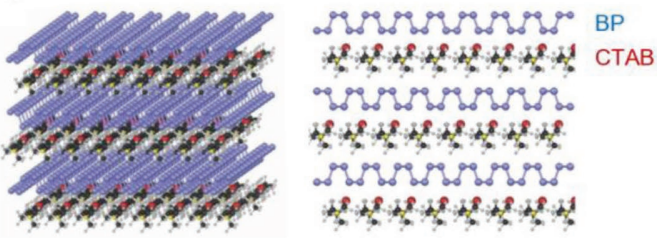

afise

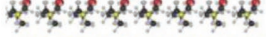

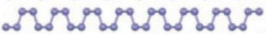

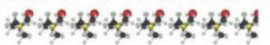
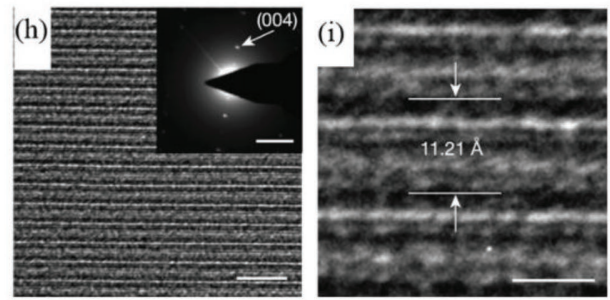

Figure 2. a,b) Schematic illustration of typical architectures of lateral (a) and vertical (b) heterostructures based on 2D materials. c) Scanning electron microscopy (SEM) image of monolayer $\mathrm{WS}_{2} / \mathrm{WSe}_{2}$ superlattice. d) Spatial maps of normalized lattice constants $\mathrm{a}_{\perp}$. e) SEAD pattern of superlattice. f) Enlarged diffraction spots as indicated in (e).g) 3D and cross-sectional views of the simulated atomic structure of the P/CTAB lattice. h,i) Crosssectional TEM images in different resolution. c-f) Reproduced with permission. ${ }^{[49]}$ Copyright 2018. American Association for the Advancement of Science. g-i) reproduced with permission. ${ }^{[57]}$ Copyright 2018, Macmillan Publishers Limited, part of Springer Nature.

on each layer of 2D crystal without direct chemical bonding to the adjacent layer. The interaction between the neighboring layers of these layered materials are characterized by van der Waals force. Thus, the highly disparate materials could be integrated without constricts of crystal lattice mismatching. In this regard, theoretical models are widely applied to understand the properties of various 2D crystals and their heterostructures. The electronic and elastic properties of 2D mono/ heterostructures are predicted through many theoretical approaches, like ab inito and tight-binding (TB) methods. ${ }^{40]}$ The excellent properties of $2 \mathrm{D}$ materials are even more pronounced when they are integrated with other functional materials to construct 2D-2D, 1D-2D, and 2D-0D heterostructures, as exemplified in Figure 1d-f. Being able to incorporate multiple electronic features into one system, the design of heterostructures has brought us versatile functionalities. The structural and electronic benefit of heterostructures formation provide a fertile ground to maximize the geometrical exposure of active edge sites and optimize the energetics and kinetics of catalytic reactions. Particularly, the merits resulting from synergism of the constituent components and the fascinating properties at the interface are tremendously interesting. It is believed that heterostructures formed by combination of two different materials play important role in catalytic reactions as "a combined-two is better than an isolated-two." [6,41] When heterostructures form, there would be variation in the work function, the position of the valence band and conduction band, and the density of states. ${ }^{[42]}$ These variations lead to entirely different electronic structures thereby endowing a great opportunity in tuning the carrier distribution and mobility for enhanced activity.

\subsection{Structural and Electronic Properties}

The heterostructures, potentially integrating the advantages and overcoming the weakness of the individual ones, usually consist of two or more distinctive components. The rational construction of the heterostructure could tune the electronic structure to realize the efficient catalytic activity due to a synergistic effect between the different components. ${ }^{[43]}$ When contacting different crystals together, charge redistribution or strain might occur between the neighboring crystals. Thus, the change of the properties, including electronic and structural ones, will be induced in each other. ${ }^{[44]}$

The heterostructure based on 2D materials can be generally classified as lateral heterostructure and vertical heterostructure (Figure 2a,b). The lateral heterostructure are constructed with different 2D crystals, which are bonded in atomic level. ${ }^{[43,45]}$ The chemical vapor phase epitaxial growth method ${ }^{[46]}$ is utilized to construct the ternary or multivariate ordered heterostructures on lateral direction. With this method, the graphene- $\mathrm{h}-\mathrm{BN}^{[47]}$ and various TMD (i.e., $\mathrm{MoS}_{2}, \mathrm{WS}_{2}$, and $\mathrm{MoTe}_{2}$ ) based heterostructures ${ }^{[48]}$ in one plane have been realized recently. Park and co-workers ${ }^{[49]}$ synthesized coherent atomically thin superlattices where $\mathrm{WS}_{2}$ and $\mathrm{WSe}_{2}$ monolayers are repeated and laterally integrated within the single layer (Figure 2c). These dislocation-free superlattices fully matched lattice constant across heterointerfaces with an isotropic lattice structure and triangular symmetry. Figure $2 d$ shows the structural information with the orientation of $\mathrm{a}_{\perp}$ (perpendicular to the heterointerfaces), provided by the electron microscope pixel array detector (EMPAD), of the whole superlattices with nanoscale resolution, revealing the lattice coherence. Furthermore, the 
(a)

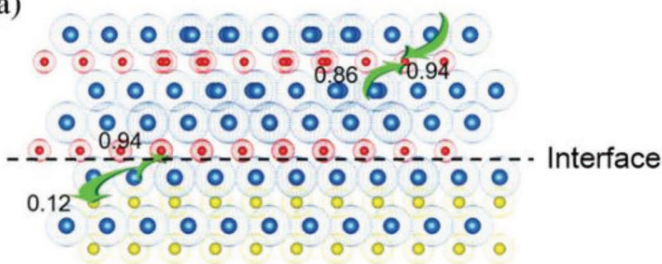

(b)

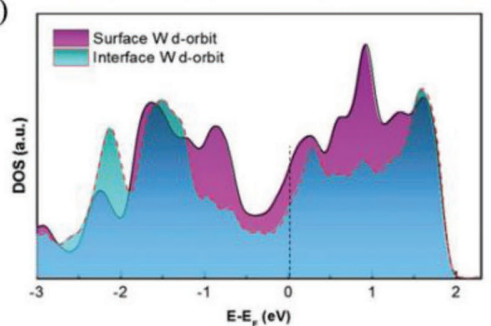

Fast in-plane electron-hole pair separation

(e)

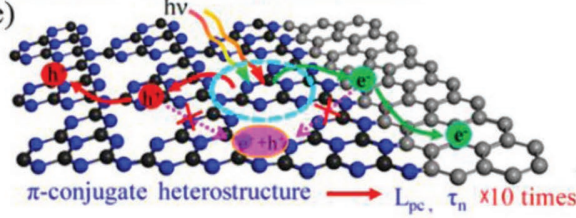

(c)

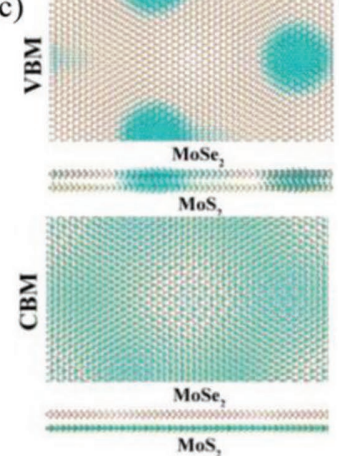

(f)

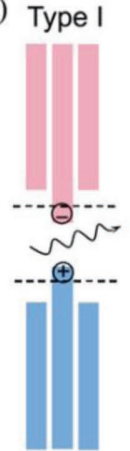

(1)

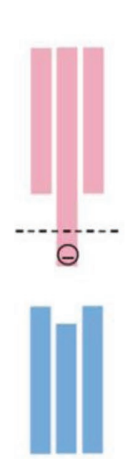

(2)

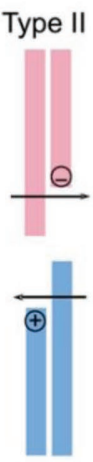

(3) (d)
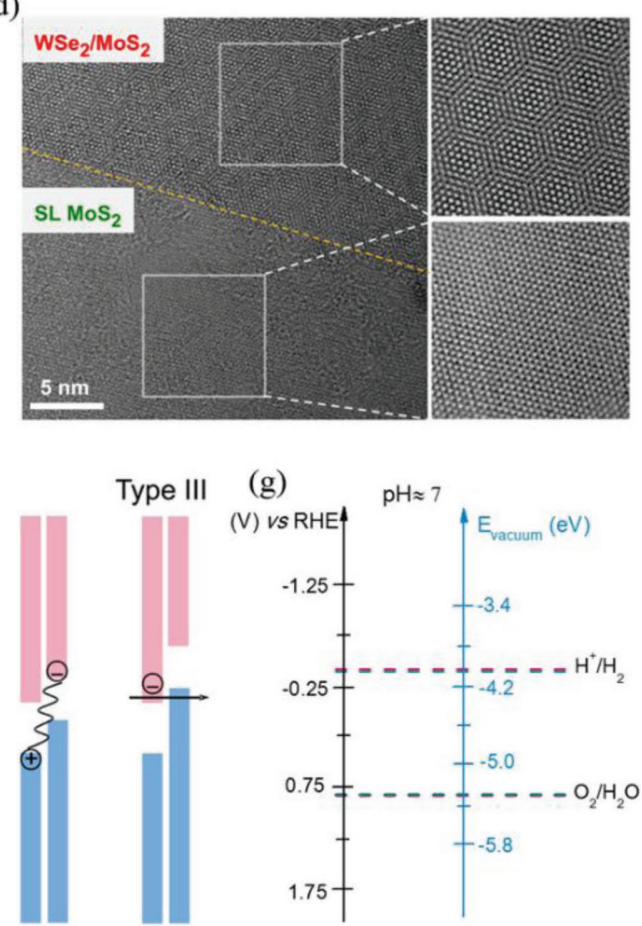

(5)

Figure 3. a) Charge redistribution in $W_{2} @ W S_{2}$ heterostructure. b) The density of states comparison of the $W$ atom on the surface and interface around the Fermi level. a,b) Reproduced with permission. ${ }^{[61]}$ Copyright 2017, Wiley-VCH. c) Top view and side view of the spatial distribution of VBM and CBM states for the Moire structure. Reproduced with permission. ${ }^{[65]}$ Copyright 2013, American Chemical Society. d) High-resolution TEM images of a boundary region of single-layer $\mathrm{MoS}_{2}$ and the hetero-bilayer, showing the resulting Moire pattern. Reproduced with permission. ${ }^{[59]}$ Copyright 2014, National Academy of Sciences. e) Schematics depicting photocarrier transfer between $C_{\text {ring }}-C_{3} N_{4}$. $L_{p c}$ and $\tau_{n}$ represent the photocarrier diffusion length and lifetime, respectively. Reproduced with permission. ${ }^{[67]}$ Copyright 2017, American Chemical Society. f) Illustration of type I, II, and III heterostructures and their applications, where red and blue indicate conduction and valence bands, respectively. Reproduced with permission. ${ }^{[69]}$ Copyright 2016 , American Physical Society. g) Redox potentials of water at $\mathrm{pH} \approx 7$.

selective-area electron diffraction (SAED) data (Figure 2e) exhibited a single-crystal-like pattern with sharp and isotropic diffraction spots. A single diffraction spot with no separation on $\mathrm{a}_{/ /}$(parallel to the hetrointerfaces) orientation confirm the perfect lattice matching. And similar lattice constants were also observed in the diffraction data corresponding to $a_{\perp}$ (Figure 2f). Such coherent superlattices with strain will endow the lateral heterostructures with targeted functionalities, including catalytic activity. Additionally, vertical heterostructures (Figure 2b) with one crystalline 2D crystal on the top of another one are widely studied. Graphene, as an excellent conductor, has been used to support other 2D nanosheets, such as topological insulators ${ }^{[50]}$ (i.e., $\mathrm{Bi}_{2} \mathrm{Se}_{3}, \mathrm{In}_{2} \mathrm{Se}_{3}$ ), semiconductors ${ }^{[51]}$ (i.e., $\mathrm{MoS}_{2}{ }^{[52]}$ ) and metals (i.e., $\mathrm{MoC}_{2}{ }^{[53]}$ ). In the past few years, a variety of TMD heterostructures have been prepared via epitaxial growth method $^{[54,55]}$ and combinatorial technologies (exfoliation and restacking). ${ }^{[56]}$ Latest, different with the previous methods, an electrochemical molecular intercalation approach was explored by Wang et al. ${ }^{[57]}$ to fabricate stable superlattices in vertical direction. As seen in Figure 2g, intercalation with cetyl-trimethylammonium bromide (CTAB) in the vander Waals interlayers of black phosphorus (BP) could produce monolayer phosphorene molecular superlattices. Compared with the interlayer distance of BP (5.24 A), that of new superlattice (Figure 2h-i) will be uniformly enlarged by two times (11.21 A). Significantly, this approach provide an opportunity to construct a wide range of functional-molecular modified superlattices with 2D materials as a versatile platform for physics studies or catalytic reactions. The similar heterostructure, consist of graphene oxide and titanium oxide, also designed through self-assembly. ${ }^{[58]}$

It is to be noted that the strong interlayer or interface coupling of charge carriers ${ }^{[59,60]}$ will be introduced when the two crystals are brought together. In this case, the charge redistribution occurs on the interface and it will tune the electronic states. As shown in Figure 3a, ${ }^{[61]}$ when connecting $\mathrm{W}_{2} \mathrm{C}$ with $\mathrm{WS}_{2}$, an apparent electron of $0.12|e|$ transfer from the $\mathrm{W}$ atoms of $\mathrm{W}_{2} \mathrm{C}$ to $\mathrm{WS}_{2}$, and $\mathrm{S}$ atoms simultaneously gain more $0.16|e|$. The density of state (DOS) spectra (Figure 3b) show that the electronic density is reduced around the Fermi level, suggesting the regulation of Gibbs free energy $\left(\Delta G_{H} *\right)$ for hydrogen adsorption on the interface and improvement of the hydrogen evolution activity at the interface. Many research groups ${ }^{[62-64]}$ also found the fine control over the edge of TMD crystals between graphene or $\mathrm{rGO}$ sheets resulted in the high electrocatalytic activity in the hydrogen evolution reaction. Besides, the lattice mismatched or rotated heterostructures, especially the 2D-2D ones, will lead to the surface reconstruction. The occurrence of the Moire pattern on the vertical heterostructure verify the spatially varying interlayer coupling strength and electrostatic potential. ${ }^{[65,66]}$ Figure $3 \mathrm{c}$ shows the calculated valence-band 
maximum (VBM) state and conduction band minimum (CBM) state of $\mathrm{MoSe}_{2} / \mathrm{MoS}_{2}$ heterostructure. The VBM state is predicted to be strongly localized, while CBM state is weakly localized. Such wave function localization were found in many 2D vdW heterostructures. As demonstrated in Figure 3d, a Moire pattern of vertical $\mathrm{WSe}_{2} / \mathrm{MoS}_{2}$ heterostructure ${ }^{[59]}$ was clearly visible in the high-resolution transmission electron microscopy (HRTEM) image. This localized state and charge transfer across the atomic planes would have major impacts on the carrier migration, electronic and chemical reactivity on the surface. For the lateral heterostructure, such as $\mathrm{C}_{\text {ring }}-\mathrm{C}_{3} \mathrm{~N}_{4}$ plane heterostructural nanosheet, ${ }^{[67]}$ this unique plane could synchronously accelerate electron-hole pair separation and electron transport via in-plane $\pi$-conjugated electric field for efficient photocatalytic water splitting (Figure 3e). And this configuration $^{[68]}$ is also fabricated to promote the electrochemically overall water splitting.

Another intriguing effect can be realized by combining two semiconducting crystals. The carrier delocalization will be induced by the sufficient hybridization, resulting in band bending and formation of a built-in potential, of atomic orbitals due to the strongly bonded interface. This structure is particularly promising for photocatalysis. Based on their band alignments, heterostructures contain three types, namely, type I, type II, and type III, which are displayed in Figure 3f. ${ }^{[69]}$ Each of these band alignments are utilized in specific system. For instance, the type I band alignments and type III are widely used in optical devices (light-emitting diodes (1)) and tunneling field effect transistors (5). Type II band alignments are very useful for solar cells (3), ${ }^{[70]}$ photocatalysis $((3) \text { and }(4))^{[7]}$ or electronic devices (2). ${ }^{[71]}$ But, when constructing the type II heterostructure for photocatalytic water splitting, the redox potentials of pure water (Figure $3 \mathrm{~g}$ ) should be carefully considered.

The following section deals with the prominent applications of 2D materials based heterostructures in catalysis. It is obvious one can see a remarkable enhancement in the case of heterostructures of optimized components as compared to either of the single components for the reason mentioned above.

\section{Promising Applications in Catalysis}

The performance of a given catalyst depends on the effort of exposing active sites on the surface. Table 1 summarizes the recent reports about heterostructures containing 2D materials. It can be envisioned that the catalytic activity, especially in hydrogen evolution reaction through water splitting and $\mathrm{CO}_{2}$ reduction for value added organic compounds, significantly improves for the heterostructures built from optimized components as compared to their single component counterparts. Notably, compared with the other hybrid materials, the highquality interfaces between 2D nanocrystal and other functional materials in 2D heterostructures could provide ideally aligned band offsets, which is essential for photocatalysis. Due to the 2D feature of these materials, tuning of electronic structure, closely related to electrocatalysis, can easily be realized via regulating the concentration of defects or strain. ${ }^{[72]}$ As such, the design of 2D materials finds a promising way for excellent performance in activity, stability, and selectivity toward a given reaction and used in industrial catalysis instead of noble metal catalysts. The 2D catalysts should also be built from elementally abundant and less expensive materials for a widespread application. Maximal exposure of active sites based on entirely earth-abundant elements with controllability and largearea uniformity is an essential requirement for practical applications. Up to know, solution processes ${ }^{[73]}$ are widely utilized to synthesize the 2D heterostructures with large-scale production. In order to fabricate the 2D heterostructure with high-quality interface, the chemical vapor deposition method is preferred. However, the large-scale production of 2D catalysts by this method is defective and challenging. Much more efforts should be made in this direction. The structural and electronic benefits of heterostructures provide a fertile ground to maximize the geometrical exposure of active edge sites and optimize the energetics and kinetics of catalytic reactions.

\subsection{Water Splitting}

The construction of various kinds of heterostructures based on 2D materials offers great opportunities for boosting the catalytic performance in both electrocatalysis and photocatalysis of water splitting reactions. Apart from introducing defects and dislocations, there will be charge transfer process across the interface as mentioned in Section 2.1. The induced charge distribution between the components, forming up the heterostructure, plays a key role in hydrogen atom adsorption and desorption kinetics. This remarkably reduces the overpotential required to derive electrocatalytic water splitting reactions. Given these merits, the semiconducting $\mathrm{MoS}_{2}$ nanosheet is coupled with the most conductive graphene via different synthesis methods (Table 1 ) and junction types in the quest for enhanced performance. The work by Dai and co-workers is a typical example representing a 0D-2D heterostructure between $\mathrm{MoS}_{2}$ and reduced graphene oxide. ${ }^{[62]} \mathrm{MoS}_{2}$ nanoparticles can be selectively grown on the surface of graphene oxide (GO) as a result of the interaction between the functional groups of GO sheet and the precursor used as a source of Mo. An appropriate solvent is required for this to achieve a well-dispersed 0D-2D heterostructure. Owing to the rapid electron transfer across the underlying $\mathrm{MoS}_{2}-\mathrm{rGO}$ network and creation of abundant active sites, this hybrid structure exhibits improved HER activity in acid solution as compared to either of the single components $\left(\mathrm{MoS}_{2}\right.$ nanoparticles or $\left.\mathrm{rGO}\right)$. It has, recently, been observed that graphene-mediated charge-transfer kinetics can result in synergizing the 2D-2D heterostructure between $\mathrm{Mo}_{2} \mathrm{C}$ and graphene. ${ }^{[7]}$ With the optimized reaction time and $\mathrm{CH}_{4}$ flow rate in chemical vapor deposition (CVD) operation, the controllable nucleation of $\mathrm{Mo}_{2} \mathrm{C}$ flakes on graphene sheet has been observed as depicted in Figure 4a. In due course of the reaction, $\mathrm{Mo}_{2} \mathrm{C}$ flakes first nucleate on already formed graphene sheet. As the reaction time increases, further nucleation of $\mathrm{Mo}_{2} \mathrm{C}$ flakes takes place which eventually coalesce into a continuous film. Figure $4 \mathrm{~b}$ demonstrates the enhanced HER activity of the heterostructure which can be attributable to the high crystallinity of the $\mathrm{Mo}_{2} \mathrm{C}$ flakes and the excellent electronic coupling to graphene, collectively contributing to rapid charge transfer kinetics for $\mathrm{H}^{+}$adsorption and $\mathrm{H}_{2}$ molecule desorption. Considering the practical application, the relatively low current density values, around tens of $\mathrm{mA}$ per square 


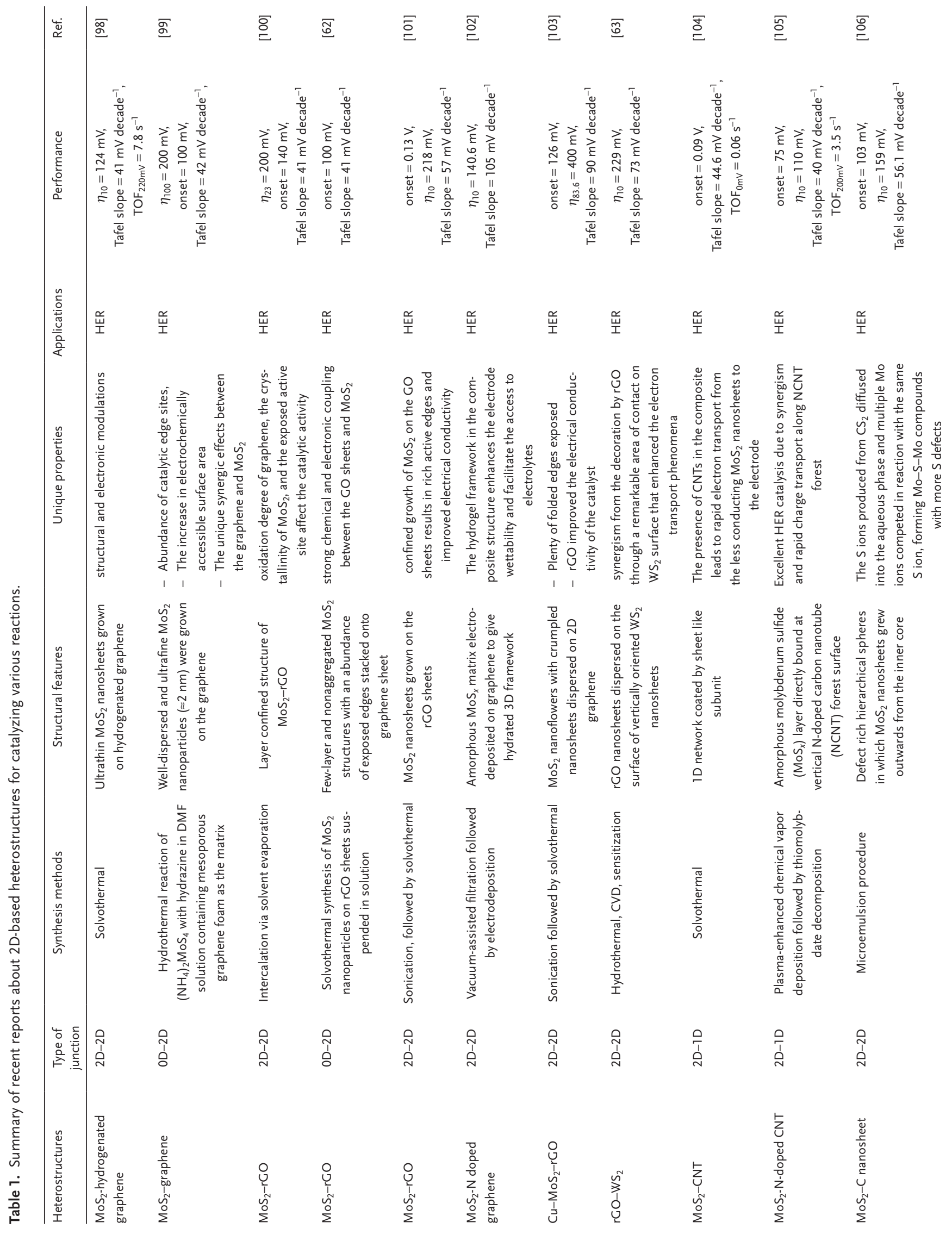




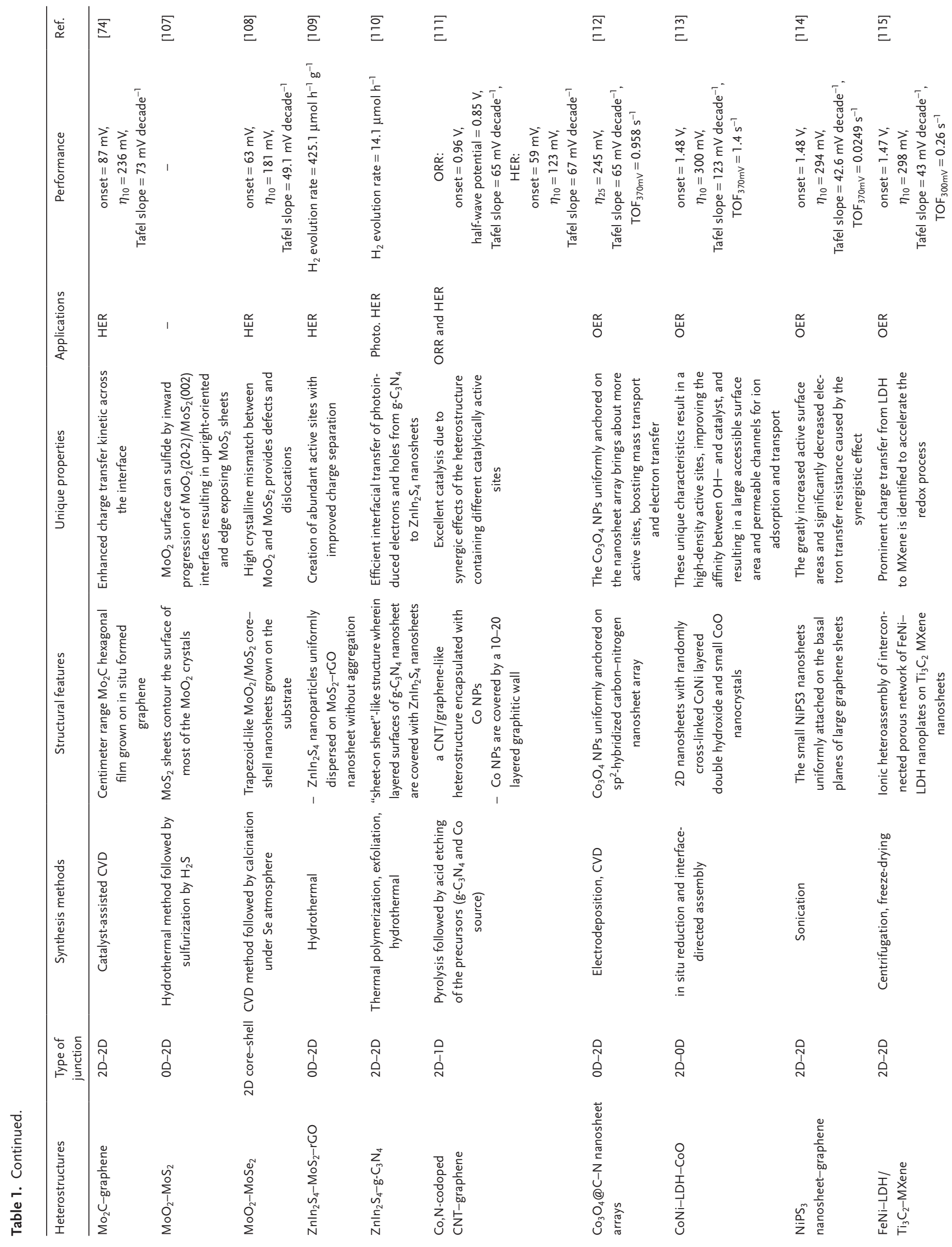




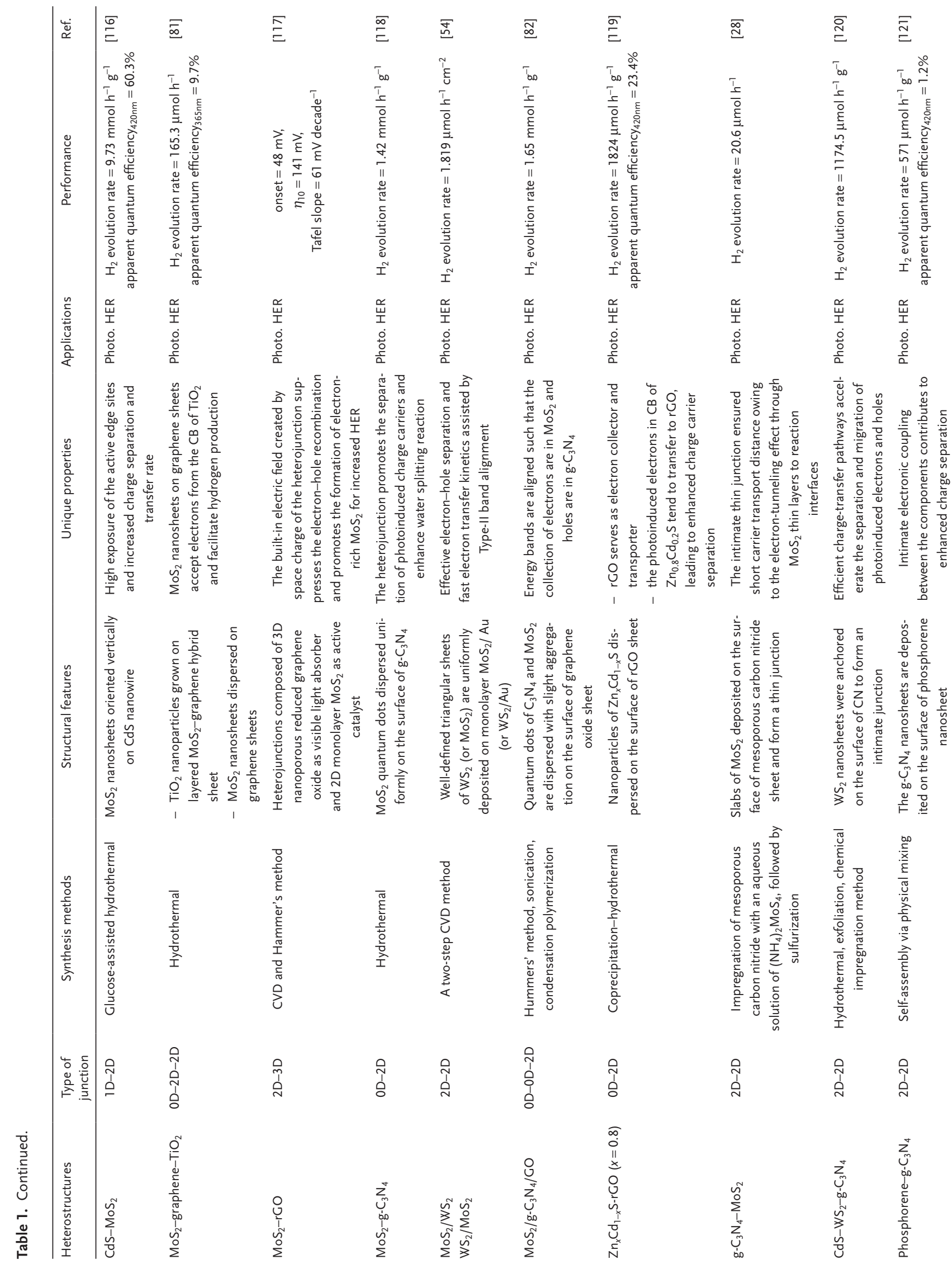




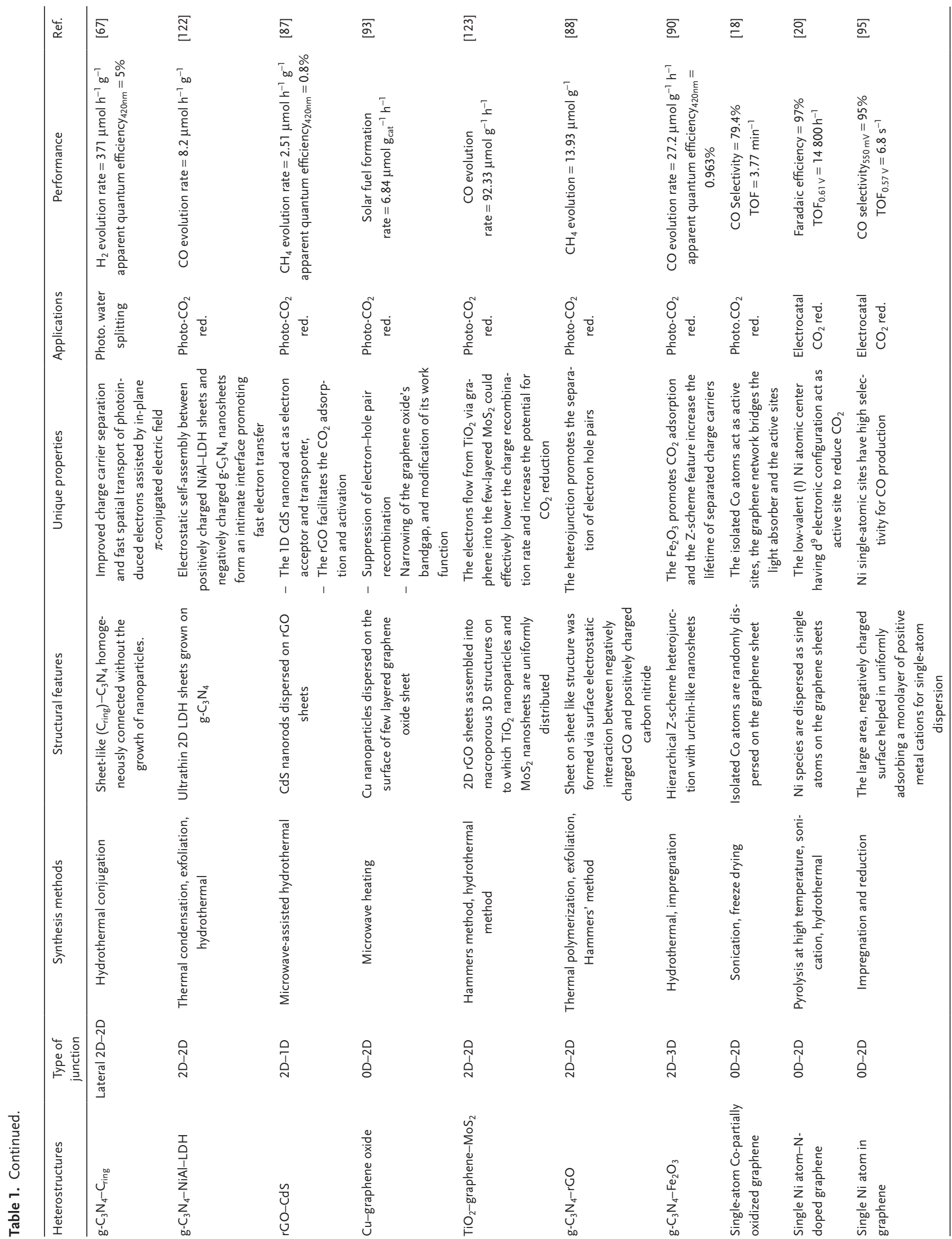


(a)

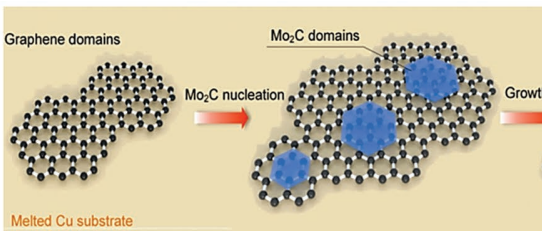

(c)

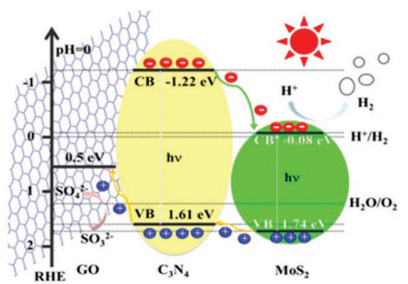

(e)

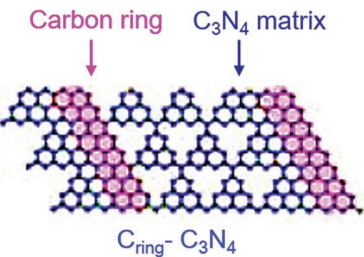

(d)

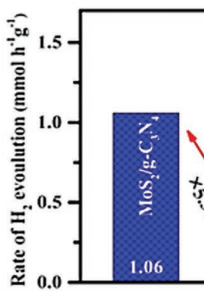

(f)

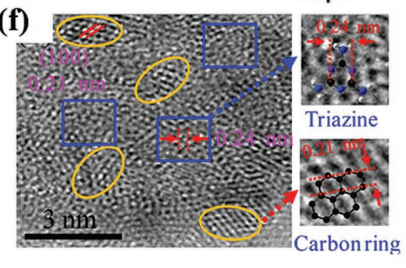

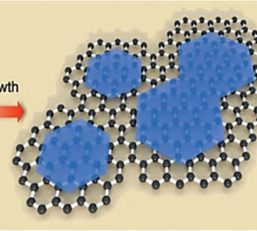

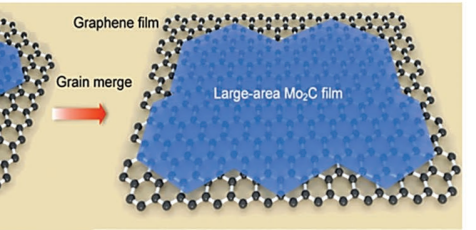

(b)
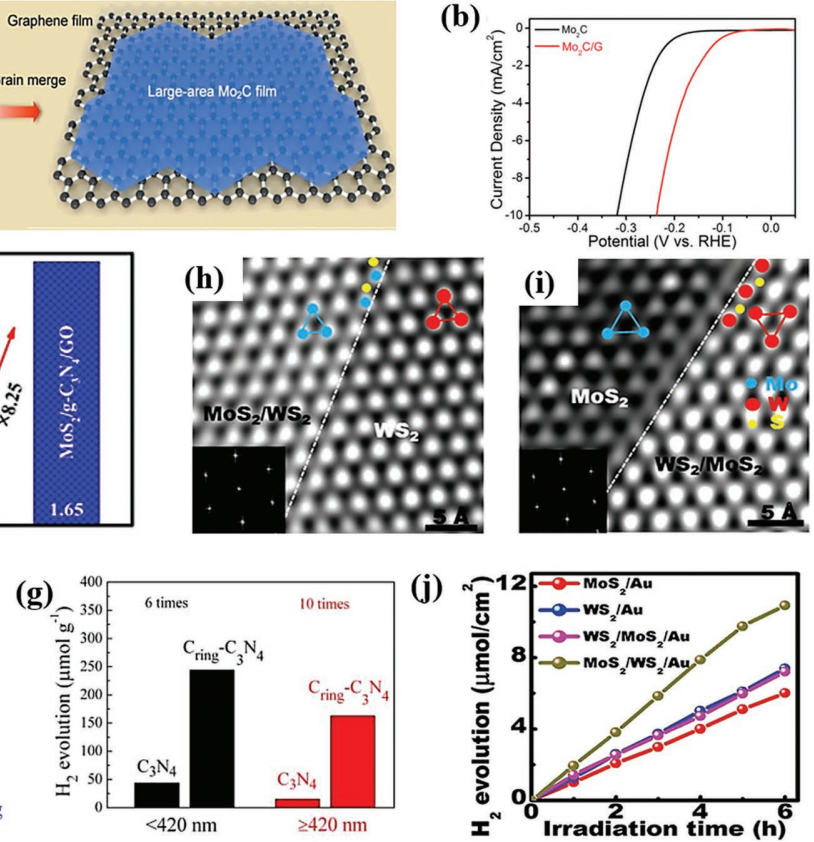

(j)

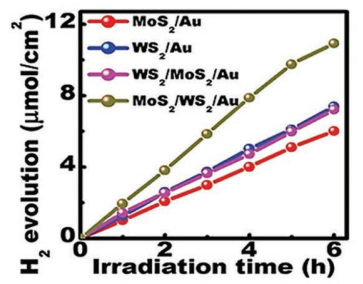

Figure 4. a) Schematics illustrating the growth of $\mathrm{Mo}_{2} \mathrm{C}$ crystals on graphene exemplifying 2D-2D heterostructure. b) Polarization curves for HER catalytic activities of $\mathrm{Mo}_{2} \mathrm{C}$ and $\mathrm{Mo}_{2} \mathrm{C} /$ graphene. a,b) Reproduced with permission. ${ }^{[4]}$ Copyright 2017, Wiley-VCH. c) Schematics of charge carrier separation across the $\mathrm{MoS}_{2} / \mathrm{g}-\mathrm{C}_{3} \mathrm{~N}_{4} / \mathrm{GO}$ interface. d) Photocatalytic HER performance depicting remarkable enhancement for the heterojunction. c,d) Reproduced with permission. ${ }^{[82]}$ Copyright 2017, American Chemical Society. e) Schematic depicting the lateral $C_{\text {ring }} / C_{3} N_{4}$ heterostructure and f) the corresponding HRTEM image. g) Photocatalytic $\mathrm{H}_{2}$ evolution under UV $(<420 \mathrm{~nm})$ and visible light $(\geq 420 \mathrm{~nm})$ per hour. e-g) Reproduced with permission. ${ }^{[67]}$ Copyright 2017, American Chemical Society. h) Atomic-resolution STEM-HAADF image from the edge of WS $\mathrm{S}_{2} / \mathrm{MoS}_{2}$ stack. i) Atomicresolution STEM-HAADF image from the edge of $\mathrm{MoS}_{2} / \mathrm{WS}_{2}$ stack. j) Photocatalytic $\mathrm{H}_{2}$ evolution curves of heterostructures in (h) and (i) under solar light irradiation. $\mathrm{h}-\mathrm{j})$ Reproduced with permission. ${ }^{[54]}$ Copyright 2016, Wiley-VCH.

centimeter, and high overpotential of these 2D heterostructured HER catalysts is a substantial challenge. Thus, exploring the efficient electrocatalysts with 2D heterostructures is critical in the future studies.

As the anodic reaction of water splitting, oxygen evolution reaction (OER) is sluggish due to involving four electrons. ${ }^{\text {[75] }}$ Some OER electrocatalysts based on 2D heterostructures are also designed for decreasing the overpotential to generate oxygen gas through splitting water. Yu and co-workers ${ }^{[76]}$ fabricated the in-plane black phosphorus $/ \mathrm{Co}_{2} \mathrm{P}$ heterostructure for electrocatalytic water splitting in alkaline media $(1.0 \mathrm{~m} \mathrm{KOH})$. The high oxygen evolution activity is also realized using $\mathrm{BP} /$ $\mathrm{Co}_{2} \mathrm{P}$ heterostructure. Besides, the vertical 2D heterostructures, such as $\mathrm{Ni}_{3} \mathrm{FeN} / \mathrm{NRGO}{ }^{[77]}$ were designed for improving OER performance. The strong coupling between $\mathrm{Ni}_{3} \mathrm{FeN}$ nanoplates and graphene support tuned the electronic structure, critical for reaction steps, of the catalyst. To be noted, the OER activity using some of 2D materials, including chalcogenides and phosphides, is controversial due to the easy oxidation of these materials under the oxygen evolution condition. The confirmation and detection of their active sites via some in situ techniques for OER are essential in the following research.

In the case of photocatalysis, the issue of band alignment comes into play apart from the advantages mentioned for electrocatalysis. The special and commonly known structure called “Type-II junction” (Section 2.1) is widely acknowledged for elongating the lifetime of charge carriers via suppressing electronhole recombination for different kinds of heterostructure. ${ }^{[78]}$.
It obvious that plethora of reports ${ }^{[79]}$ have been made in attempt to boost the photocatalytic performance of $\mathrm{TiO}_{2}$ since its first observation by Fujishima and Honda. ${ }^{[0]}$ The synergetic effect between $\mathrm{MoS}_{2}$ and graphene in cocatalyzing HER on the surface of $\mathrm{TiO}_{2}$ can be considered as one of the efforts. ${ }^{[81]}$ This heterostructure has two prominent advantages: i) graphene has high electron mobility, and hence the electrons on the conduction band (CB) of $\mathrm{TiO}_{2}$ can be injected to the graphene sheet and experience accelerated kinetics; ii) the $\mathrm{MoS}_{2}$ nanosheets that are dispersed on the graphene sheet can accept electrons and act as active sites for the photocatalysis. In different instances, graphene is frequently used as charge transport platform owing to its high carrier mobility. The ternary heterostructure built from $\mathrm{MoS}_{2}$ quantum dots (QDs), g- $\mathrm{C}_{3} \mathrm{~N}_{4}$ QDs, and graphene sheet results in junction system possessing improved interfacial contact between the QDs and the nanosheets along with the facilitated collection of electrons in $\mathrm{MoS}_{2}$ and holes

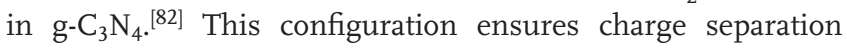
and effectively suppress charge recombination (Figure 4c). The $\mathrm{MoS}_{2}$ QDs are closely spaced with those of $\mathrm{g}-\mathrm{C}_{3} \mathrm{~N}_{4}$ which is intimately contacted with graphene, depicting the junctions of $\mathrm{MoS}_{2}$ to $\mathrm{g}-\mathrm{C}_{3} \mathrm{~N}_{4}$ to graphene. Thus, such composite absorbs light in a wide range of spectrum and experiences high charge separation efficiency than the individual ones. This guarantees its improved performance in photocatalytic HER (Figure 4d). The nitrogen sites of $\mathrm{g}_{-} \mathrm{C}_{3} \mathrm{~N}_{4}$ have lone pair of electrons which would confer an ideal platform for an intimate connection of components in heterostructures. ${ }^{[83]}$ This can be evidenced from 
the in-plane heterostructure built from $\mathrm{g}-\mathrm{C}_{3} \mathrm{~N}_{4}$ and $\mathrm{C}$ ring. ${ }^{[67]}$ Such in-pane heterostructure illustrated in Figure $4 \mathrm{e}$, having a pronounced $\pi$-conjugation, ensures enhanced photocarrier separation via swiftly trapping photoexcited electrons and driving them to suitable locations for catalysis. It is obvious from the HRTEM image in Figure $4 \mathrm{f}$ that the $\mathrm{C}$ ring (represented by orange colored elliptical shape) is randomly distributed on the basal plane of $\mathrm{g}-\mathrm{C}_{3} \mathrm{~N}_{4}$. There is remarkable amount of $\mathrm{sp}^{2}$-hybridized electronic structure that avails more electrons around the Fermi level for suppressing charge carrier recombination and enhancing visible light absorption. As compared to the pristine $\mathrm{g}-\mathrm{C}_{3} \mathrm{~N}_{4}$, there is a 10 time increment in the photocatalytic hydrogen evolution rate for g- $\mathrm{C}_{3} \mathrm{~N}_{4}-\mathrm{C}_{\text {ring }}$ heterostructure under visible light irradiation (Figure 4g).

The very recent report by Qiao and co-workers ${ }^{[84]}$ reveals a metal-free heterojunction made via mechanical mixing of few layered phosphorene and $\mathrm{g}-\mathrm{C}_{3} \mathrm{~N}_{4}$ sheet (2D-2D). It behaves like a straddled type-I configuration wherein the photoinduced electrons in $\mathrm{CB}$ of $\mathrm{g}_{-} \mathrm{C}_{3} \mathrm{~N}_{4}$ flow to the $\mathrm{CB}$ of phosphorene to do their job of catalysis. The strong electronic coupling, verified by the migration of electron from $\mathrm{g}-\mathrm{C}_{3} \mathrm{~N}_{4}$ to phosphorene, made an intact contact of g- $\mathrm{C}_{3} \mathrm{~N}_{4}$ on the surface of few layered phosphorene. Phosphorene by itself does not have remarkable photocatalytic activity. The heterostructure endows a high interfacial charge transfer between these 2D components and a modification of the electronic structure. The 2D-2D heterojunction between phosphorene and g- $\mathrm{C}_{3} \mathrm{~N}_{4}$, with optimized component ratio, could boost the photocatalytic HER performance considerably. Moreover, typical TMD materials, such as $\mathrm{MoS}_{2}$ and $\mathrm{WS}_{2}$ (as $\mathrm{MoS}_{2} / \mathrm{WS}_{2}$ or $\mathrm{WS}_{2} / \mathrm{MoS}_{2}$ depending on temperature of CVD reaction), have been brought to one another to give vertically oriented 2D-2D heterojunction on Au foil. ${ }^{[54]}$ Distinct crystalline features can be substantiated in Figure $4 \mathrm{~h}-\mathrm{i}$ for $\mathrm{WS}_{2} /$ $\mathrm{MoS}_{2}$ and $\mathrm{MoS}_{2} / \mathrm{WS}_{2}$, respectively. The white dashed line indicates the edge of the upper domain and the two fitted triangular lattices (in red and blue). Particularly, the vertically oriented $\mathrm{MoS}_{2} / \mathrm{WS}_{2}$ behave like Type-II heterostructure ensuring elongated carrier lifetime and suppressed recombination rate. This can be validated from the enhanced photocatalytic hydrogen evolution rate observed for this sample in Figure $4 \mathrm{j}$.

\section{2. $\mathrm{CO}_{2}$ Reduction}

The reduction of $\mathrm{CO}_{2}$ involves the breaking of the $\mathrm{C}=\mathrm{O}$ bond and the formation of products such as carbon monoxide (CO), formate $(\mathrm{CHOO})$, formaldehyde $(\mathrm{HCHO})$, methanol $\left(\mathrm{CH}_{3} \mathrm{OH}\right)$, methane $\left(\mathrm{CH}_{4}\right)$, ethanol $\left(\mathrm{C}_{2} \mathrm{H}_{4} \mathrm{OH}\right)$, etc. Unlike HER, the reduction of $\mathrm{CO}_{2}$ is challenging as it requires multistep reactions with more electron cost. ${ }^{[85]}$ Moreover, the competitive reaction of HER can easily take off as a side reaction. This necessitates the design of catalysts with high selectivity that promote $\mathrm{CO}_{2}$ reduction and suppress HER. Heterostructure of 2D materials can be a promising platform. Particularly, graphene and g- $\mathrm{C}_{3} \mathrm{~N}_{4}$ are acknowledged for being excellent support materials in photocatalyzing $\mathrm{CO}_{2}$ reduction; they maximize specific surface area and contribute to proliferation of active sites. Moreover, the interaction between graphene and $\mathrm{CO}_{2}$ takes a special advantage. There is also a delocalized $\pi-\pi$ conjugation system in $\mathrm{CO}_{2}$ molecule. This $\pi-\pi$ conjugation interaction between $\mathrm{CO}_{2}$ and graphene could eases $\mathrm{CO}_{2}$ adsorption and activation. ${ }^{[86,87]}$ Ong et al. ${ }^{[88]}$ have experimentally demonstrated this interaction using a 2D-2D hybrid structure obtained via $\pi-\pi$ stacking and electrostatic attraction between rGO and g- $\mathrm{C}_{3} \mathrm{~N}_{4}$ following protonation for surface charge modification. The SEM image in Figure 5a shows that "sheet on sheet" like structure, with distinct feature as revealed in the inset. At the interface of g- $\mathrm{C}_{3} \mathrm{~N}_{4}$ and $\mathrm{rGO}$, the photoexcited electrons at the CB of g- $\mathrm{C}_{3} \mathrm{~N}_{4}$ percolate to the $\mathrm{rGO}$ sheet which has superior electron conductivity and high charge storage capacity. The high rate of $\mathrm{CH}_{4}$ (product of $\mathrm{CO}_{2}$ reduction) production, from optimum amount of components in the heterostructure, is attributable to this fact. As can be seen in Figure 5b, the performance of pure g- $\mathrm{C}_{3} \mathrm{~N}_{4}$ is low due to the electron-hole recombination following its moderate bandgap. This is a common problem for singe component photocatalysts. Using two different semiconductors, a configuration known as Z-scheme solves this problem via promoting the separation of the electron-hole pairs and enhancing the availability of electrons at CB in one of the semiconductors. ${ }^{[89,90]}$ Figure 5c illustrates the HRTEM image of heterojunction constructed from $\mathrm{Fe}_{2} \mathrm{O}_{3}$ and g- $\mathrm{C}_{3} \mathrm{~N}_{4}$ based on this context. ${ }^{[0]}$ The distinct interface of the two components can be clearly identified through the dark dotted line that are configured in the form of the Z-scheme (Figure 5d). Interesting phenomena occurs at the interface. Assisted by the internal static electric field, the photoinduced electrons in CB of $\alpha-\mathrm{Fe}_{2} \mathrm{O}_{3}$ flow down and combine with the holes in valence band (VB) of g- $\mathrm{C}_{3} \mathrm{~N}_{4}$. This avails more electrons for photocatalysis which can be corroborated from a 2.2 time higher rate of CO evolution for $\alpha-\mathrm{Fe}_{2} \mathrm{O}_{3}-\mathrm{g}-\mathrm{C}_{3} \mathrm{~N}_{4}$ heterostructure than that produced by g- $\mathrm{C}_{3} \mathrm{~N}_{4}$ alone (Figure $5 \mathrm{e}$ ).

From various reports ${ }^{[91]}$ about the electronic structure of graphene oxide, it can be envisioned that the bandgap of GO is still too large for visible light response. Meanwhile, Cu-based catalysts are known for effectively electrocatalytic reduction of $\mathrm{CO}_{2}$ to liquid products. ${ }^{\left[{ }^{92}\right]}$ Controllable dispersion of $\mathrm{Cu}$ nanoparticles on the surface of GO can sum up the advantageous features of $\mathrm{Cu}$ and $\mathrm{GO}$ as can be exemplified from the work of Chenand co-workers. ${ }^{[93]}$ Through a one-pot microwave method that involves mixing of GO with metal precursor, they found $\mathrm{a} \approx 4-5 \mathrm{~nm}$ size of $\mathrm{Cu}$ NPs distributed on the GO surface (Figure $5 f$ ). The redox level of GO is found to be tunable with extent of $\mathrm{Cu}$ decoration (Figure $5 \mathrm{~g}$ ) in $\mathrm{Cu}-\mathrm{GO}$ hybrid enabling highly selective generation of hydrocarbons from $\mathrm{CO}_{2}$. At the interface of the heterostructure, electrons transfer from $\mathrm{GO}$ to $\mathrm{Cu}$ nanoparticles favors charge separation and suppresses charge recombination. Thus, a 60 time higher rate of $\mathrm{CO}_{2}$ reduction was exhibited in the heterostructure as compared to the pristine component (Figure 5h). A step forward from metal nanoparticles, the current paradigm about metal-2D combination deals with single metal atom implantation on the 2D framework. The isolated metal atoms act as efficient active sites for $\mathrm{CO}_{2}$ reduction as well as the 2D network that immobilizes the active site and assists the charge transfer kinetics. ${ }^{[20,94-96]}$ Graphene derivative materials are ideal scaffolds for hosting single metal atoms. Their negatively charged surface contributes in uniformly anchoring the positive single-atom cations with maximal density. As compared to their nanoparticle counterparts, 


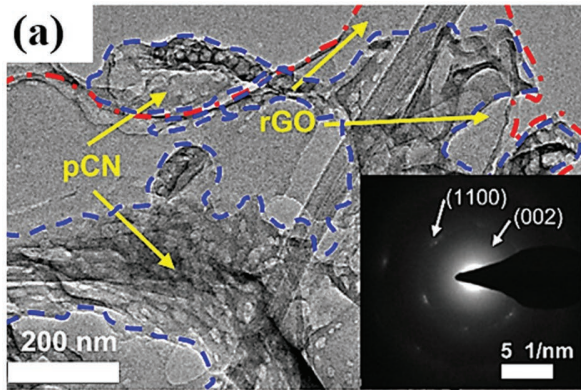

(b)
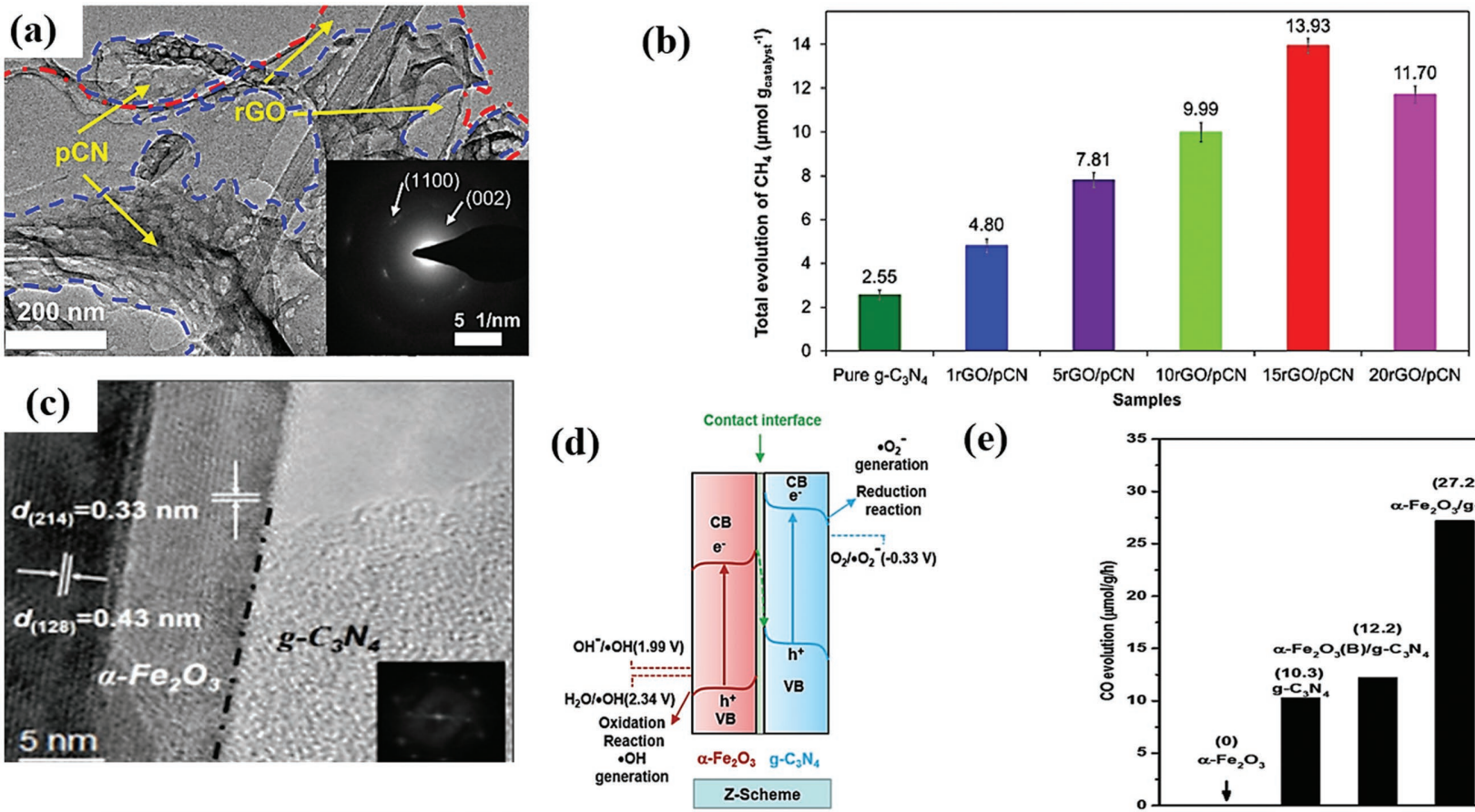

(e)
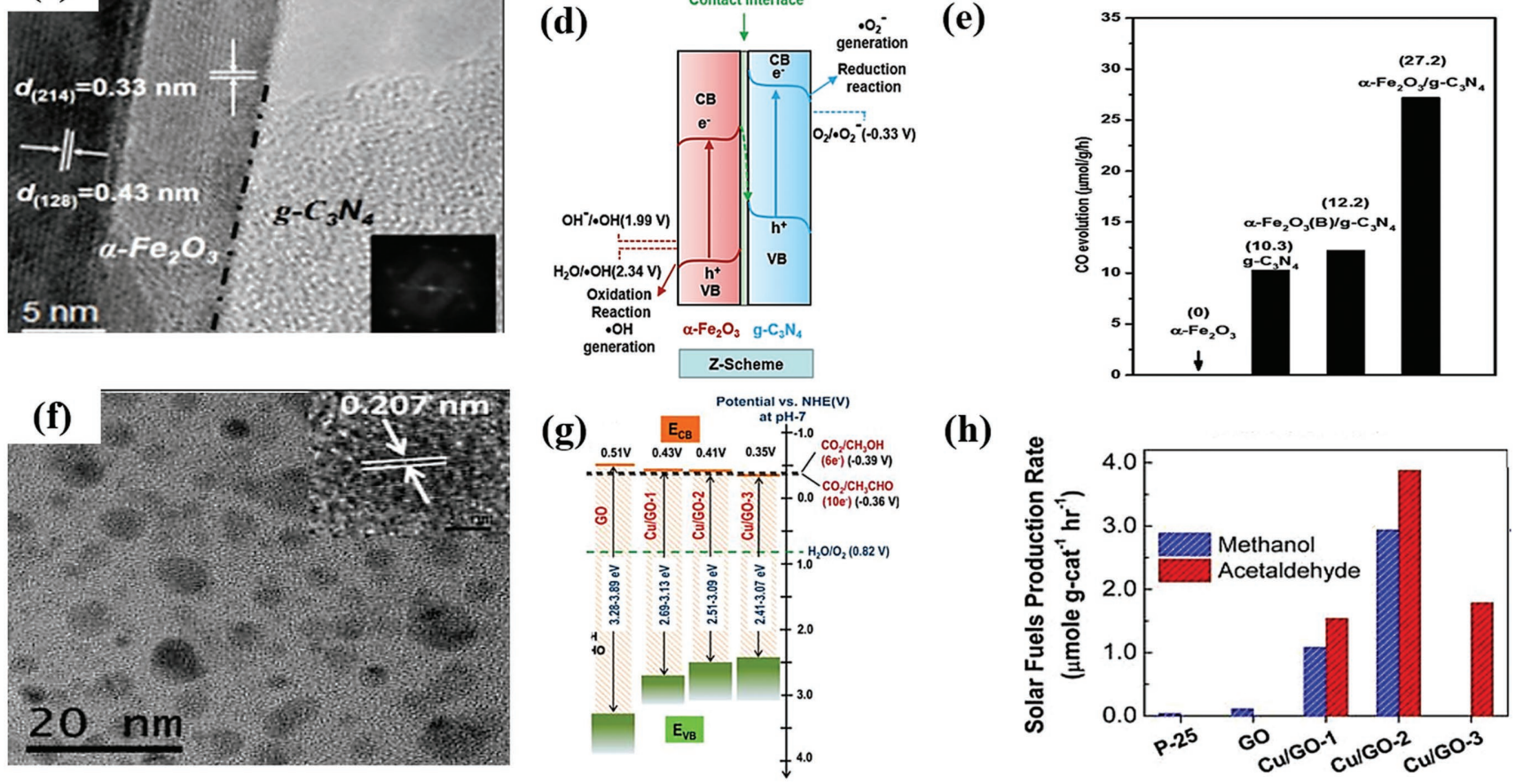

(h)

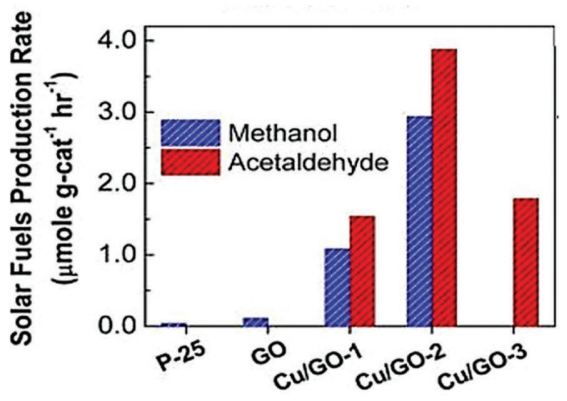

Figure 5. a) TEM image of protonated graphitic carbon nitride-reduced graphene oxide ( $\mathrm{rCO}-\mathrm{pCN}$ ) composite materials. b) Photocatalytic $\mathrm{CH}_{4}$ production rate using various samples evidencing the optimized composite with the highest rate. a,b) Reproduced with permission. ${ }^{[88]}$ Copyright 2015 , Elsevier Ltd. c) HRTEM image of $\mathrm{Fe}_{2} \mathrm{O}_{3}-\mathrm{g}$ - $\mathrm{C}_{3} \mathrm{~N}_{4}$ composite with distinct interface. d) Schematic showing the Z-scheme type heterostructure between $\mathrm{Fe}_{2} \mathrm{O}_{3}$ and $\mathrm{g}-\mathrm{C}_{3} \mathrm{~N}_{4}$. e) Photocatalytic $\mathrm{CO}$ production rate as a $\mathrm{CO}_{2}$ reduction product using evidencing the heterostructure with the highest rate. c-e) Reproduced with permission. ${ }^{[90]}$ Copyright 2018, Wiley-VCH. f) TEM (inset HRTEM) image of Cu-CO heterostructure. g) Band edge positions for various $\mathrm{Cu}-\mathrm{CO}$ rations relative to $\mathrm{CO}_{2} / \mathrm{CH}_{3} \mathrm{OH}$ and $\mathrm{CO}_{2} / \mathrm{CH}_{3} \mathrm{CHO}$ formation potentials. h) Photocatalytic $\mathrm{CO}_{2}$ reduction performance (fuel production rate) different ratio of $\mathrm{Cu}-\mathrm{GO}$ depicting that $\mathrm{Cu} / \mathrm{GO}-2$ is the optimum one. $\mathrm{f}-\mathrm{h}$ ) Reproduced with permission. ${ }^{[93]}$ Copyright 2014, American Chemical Society.

isolated atoms have high activity and selectivity as has recently been exhibited from single Co atom ${ }^{[96]}$ and single $\mathrm{Ni}$ atom in graphene ${ }^{[20,95]}$ for electrocatalytic $\mathrm{CO}_{2}$ reduction. Figure 6a shows HAADF-STEM image illustrating Co single atom dispersed with random distribution (yellow circles) on graphene. It has been observed that the metal-graphene contact is not a mere of physical adsorption rather there exists a chemical bond between isolated cobalt atom and the carbon through residual oxygen moieties on the surface of graphene (inset of Figure 6d). This special configuration renders the expected performance enhancement in photocatalytic $\mathrm{CO}$ evolution as compared to physically attached Co-graphene hybrid or pure graphene (Figure 6d). Unlike the metal nanoparticles dispersion, isolated single atoms guarantees a welldefined active site for studying the mechanism. For instance,
Liu and co-workers ${ }^{[20]}$ have recently employed operando X-ray absorption and photoelectron spectroscopy measurements to identify monovalent nickel $\left(\mathrm{Ni}^{+}\right)$single-atom center with $\mathrm{d}^{9}$ electronic configuration as catalytic active sites. This observation was made in a synthesized material of isolatedsingle Ni atom anchored in N-doped graphene. The bright spots in Figure 6b of HAADF-STEM image represent the mentioned Ni-single atom without any cluster of nanoparticles. There exists a spontaneous charge transfer from monovalent $\mathrm{Ni}$ atom to the carbon atom of $\mathrm{CO}_{2}$, which eases the reduction process. As shown in Figure 6e, the excellent performance for electrochemical production of $\mathrm{CO}$ gas can be realized from the specific current density of $350 \mathrm{Ag}_{\mathrm{cat}}{ }^{-1}$ at the overpotential of $0.6 \mathrm{~V}$. The work by Jiang et al. ${ }^{\left[{ }^{[5]}\right]}$ is another indicative for active single $\mathrm{Ni}$ atom anchored in graphene 

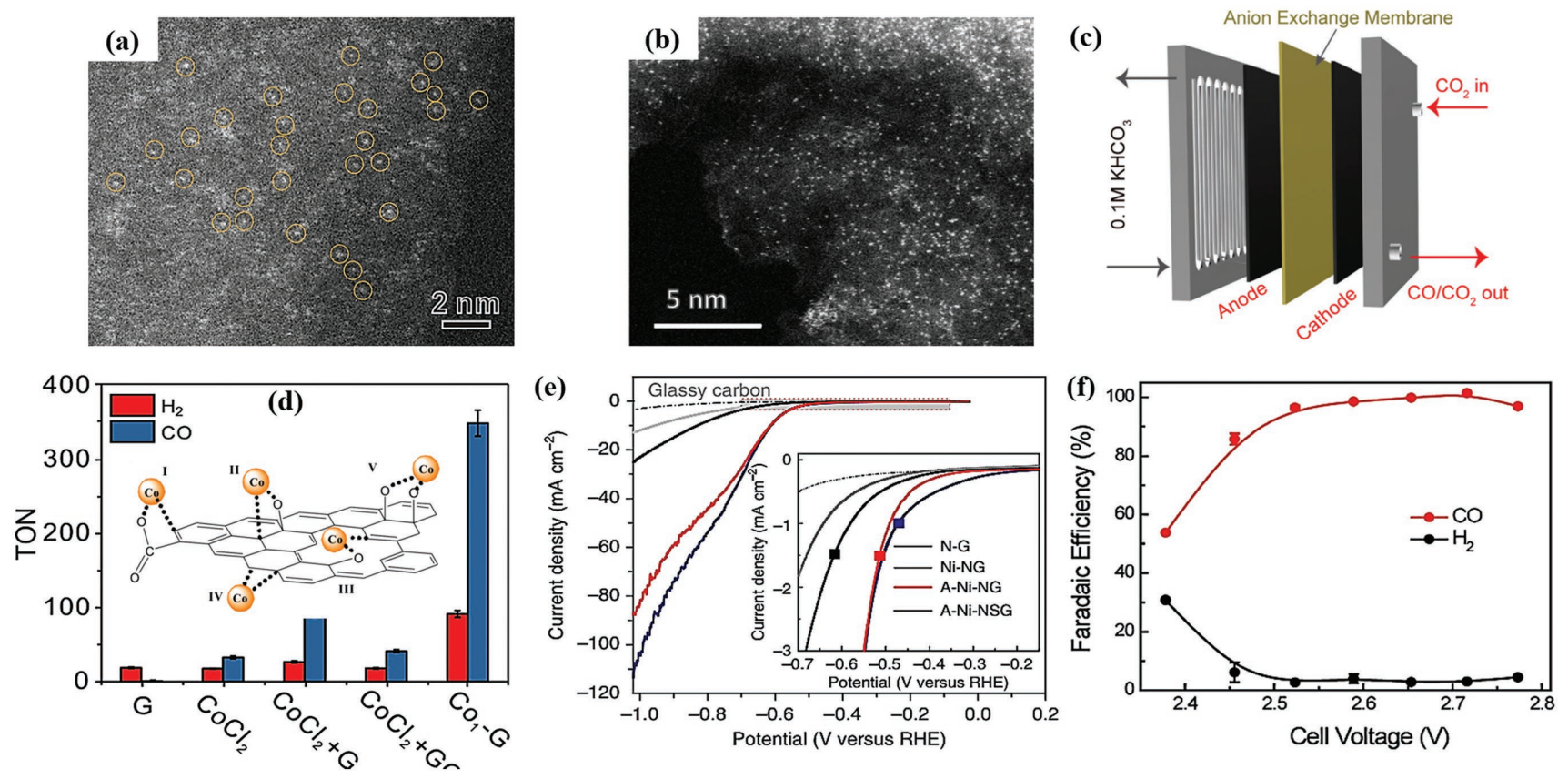

Figure 6. a,b) HAADF-STEM images for a single Co atom (yellow circle) dispersed in a graphene matrix (a) and a single Ni atom dispersed in nitrogen-doped graphene (b). c) Setup of anion membrane electrode assembly for suppressing HER. d) Electrocatalytic $\mathrm{CO}_{2}$ reduction performance depicted in terms of turnover number (TONs) of $\mathrm{CO}$ and $\mathrm{H}_{2}$ production by $\mathrm{Co}$ (single atom)-graphene nanosheets (inset: schematics of showing the bonding of $\mathrm{Co}$ with graphene framework). e) Linear sweep voltammetry curves obtained in $\mathrm{CO}_{2}$-saturated $0.5 \mathrm{M} \mathrm{KHCO}_{3}$ solution for $\mathrm{CO}_{2}$ reduction performance ( $\mathrm{N}$ - $\mathrm{G}$, nitrogenated graphene; Ni-NG, metallic Ni-nanoparticle-decorated nitrogen-doped graphene; without sulfur precursor (A-Ni-NG), with sulfur precursor (A-Ni-NSG)). f) Faradaic efficiency of $\mathrm{H}_{2}$ and $\mathrm{CO}$ production from the setup in (c) evidencing high selectivity for CO production on the surface of single-atom-graphene heterostructure. a,b) Reproduced with permission. ${ }^{\left[{ }^{18]}\right.}$ Copyright 2018, Wiley-VCH. c,f) Reproduced with permission. ${ }^{[95]}$ Copyright 2018, The Royal Society of Chemistry. d,e) Reproduced with permission. ${ }^{[20]}$ Copyright 2018, Macmillan Publishers Limited, part of Springer Nature.

network. They prevented direct contact between water and the catalyst to suppress the competing hydrogen evolution reaction by using anion membrane electrode assembly as shown in Figure 6c. It is evident from Figure $6 \mathrm{f}$ that the selectivity toward $\mathrm{CO}$ production goes to $\approx 97 \%$ while that of $\mathrm{H}_{2}$ evolution is only $4 \%$; and the accumulated $\mathrm{CO}$ production reaches $>630 \mathrm{~mL}$ within $8 \mathrm{~h}$ of the electrocatalytic reaction. Given the fact that the 2D materials are ideal platforms to uniformly and densely disperse isolated single metal atoms, several beneficial properties can be envisioned from such interface in terms of mechanistic study and performance enhancement efforts. Nevertheless, the overpotentials for $\mathrm{CO}_{2}$ reduction reaction based on 2D heterostructured electrocatalysts remain substantially larger than the thermodynamic ones. This is due to the linear scaling of the binding energy of the intermediate products. ${ }^{\text {[97] }}$ Much more theoretical and experimental strategies should be developed to further improve the thermodynamic initiation and kinetics.

\section{Conclusions and Perspectives}

Heterostructures confer appealing etiquettes for catalysis as "a combined-two is better than an isolated-two." A plethora of advantageous features come to appear when the heterostructures are built from 2D materials. For instance, the electronic and structural variations endow a great opportunity in tuning the carrier distribution and mobility for enhanced activity.
Moreover, some sorts of defects and dislocations derived from heterostructure formation are also appreciable for catalysis. The interface between two components will provide an opportunity to construct a microreactor. The recent progress on design and development of 2D based heterostructures will expectedly boost more research interests and efforts. Intriguing 2D materials such as graphene, g- $\mathrm{C}_{3} \mathrm{~N}_{4}$, and $\mathrm{MoS}_{2}$ have been frequently employed to design a novel heterostructure with various junction type and interesting results have been communicated. Another choice, i.e., transition metal phosphorus trichalcogenides with magnetic property, can be considered in the future. This will further widen the horizon of the arena with promising features for versatile catalytic applications.

\section{Acknowledgements}

T.A.S. and F.M.W. contributed equally to this work. This work was supported by National Natural Science Foundation of China (Grant Nos. 6162540, 61474033, 61574050, 11674072, and 21703047), Ministry of Science and Technology of China (No. 2016YFA0200700), Strategic Priority Research Program of the Chinese Academy of Sciences (Grant No. XDA09040201), and CAS Key Laboratory of Nanosystem and Hierarchical Fabrication.

\section{Conflict of Interest}

The authors declare no conflict of interest. 


\section{Keywords}

2D materials, catalysis, heterostructures, synergism

Received: July 27, 2018

Revised: August 21, 2018

Published online:

[1] a) W. E. Buhro, V. L. Colvin, Nat. Mater. 2003, 2, 138; b) J. N. Tiwari, R. N. Tiwari, K. S. Kim, Prog. Mater. Sci. 2012, 57, 724; c) I. Batra, Phys. Rev. B 1986, 34, 8246; d) R. Mas-Balleste, C. Gomez-Navarro, J. Gomez-Herrero, F. Zamora, Nanoscale 2011, $3,20$.

[2] a) K. S. Novoselov, A. K. Geim, S. V. Morozov, D. Jiang, Y. Zhang, S. V. Dubonos, I. V. Grigorieva, A. A. Firsov, Science 2004, 306, 666; b) X. Huang, X. Qi, F. Boey, H. Zhang, Chem. Soc. Rev. 2012, 41, 666; c) Q. Xiang, B. Cheng, J. Yu, Angew. Chem., Int. Ed. 2015, 54, 11350; d) K. Chang, X. Hai, H. Pang, H. Zhang, L. Shi, G. Liu, H. Liu, G. Zhao, M. Li, J. Ye, Adv. Mater. 2016, 28, 10033; e) B. F. Machado, P. Serp, Catal. Sci. Technol. 2012, 2, 54.

[3] P. Miró, M. Audiffred, T. Heine, Chem. Soc. Rev. 2014, 43, 6537.

[4] D. Voiry, J. Yang, M. Chhowalla, Adv. Mater. 2016, 28, 6197.

[5] B. Luo, G. Liu, L. Wang, Nanoscale 2016, 8, 6904.

[6] D. Deng, K. Novoselov, Q. Fu, N. Zheng, Z. Tian, X. Bao, Nat. Nanotechnol. 2016, 11, 218.

[7] F. Wang, T. A. Shifa, X. Zhan, Y. Huang, K. Liu, Z. Cheng, C. Jiang, J. He, Nanoscale 2015, 7, 19764.

[8] P. Sun, R. Ma, X. Bai, K. Wang, H. Zhu, T. Sasaki, Sci. Adv. 2017, 3, e1602629.

[9] a) H. Zhang, ACS Nano 2015, 9, 9451; b) M. Xu, T. Liang, M. Shi, H. Chen, Chem. Rev. 2013, 113, 3766; c) B. Dubertret, T. Heine, M. Terrones, Acc. Chem. Res. 2015, 48, 1.

[10] a) S. Z. Butler, S. M. Hollen, L. Cao, Y. Cui, J. A. Gupta, H. R. Gutiérrez, T. F. Heinz, S. S. Hong, J. Huang, A. F. Ismach, ACS Nano 2013, 7, 2898; b) G. R. Bhimanapati, Z. Lin, V. Meunier, Y. Jung, J. Cha, S. Das, D. Xiao, Y. Son, M. S. Strano, V. R. Cooper, ACS Nano 2015, 9, 11509; c) A. Neto, K. Novoselov, Mater. Express 2011, 1, 10.

[11] A. McKenna, G. M. Findlay, J. A. Gagnon, M. S. Horwitz, A. F. Schier, J. Shendure, Science 2016, 353, aaf7907.

[12] X. Huang, C. Tan, Z. Yin, H. Zhang, Adv. Mater. 2014, 26, 2185.

[13] F. Wang, P. He, Y. Li, T. A. Shifa, Y. Deng, K. Liu, Q. Wang, F. Wang, Y. Wen, Z. Wang, Adv. Funct. Mater. 2017, 27, 1605802.

[14] a) D. Chen, H. Zhang, Y. Liu, J. Li, Energy Environ. Sci. 2013, 6, 1362; b) J. Yu, J. Jin, B. Cheng, M. Jaroniec, J. Mater. Chem. A 2014, 2, 3407 .

[15] a) F. Bonaccorso, L. Colombo, G. Yu, M. Stoller, V. Tozzini, A. C. Ferrari, R. S. Ruoff, V. Pellegrini, Science 2015, 347, 1246501; b) A. Peigney, C. Laurent, E. Flahaut, R. Bacsa, A. Rousset, Carbon 2001, 39, 507

[16] a) Y. Sun, Q. Wu, G. Shi, Energy Environ. Sci. 2011, 4, 1113; b) N. Yang, J. Zhai, D. Wang, Y. Chen, L. Jiang, ACS Nano 2010, $4,887$.

[17] Y. Tang, X. Hu, C. Liu, Phys. Chem. Chem. Phys. 2014, 16, 25321.

[18] C. Gao, S. Chen, Y. Wang, J. Wang, X. Zheng, J. Zhu, L. Song, W. Zhang, Y. Xiong, Adv. Mater. 2018, 30, 1704624.

[19] G. Gao, Y. Jiao, E. R. Waclawik, A. Du, J. Am. Chem. Soc. 2016, $138,6292$.

[20] H. B. Yang, S. F. Hung, S. Liu, K. Yuan, S. Miao, L. Zhang, X. Huang, H. Y. Wang, W. Cai, R. Chen, J. Gao, X. Yang, W. Chen, Y. Huang, H. M. Chen, C. M. Li, T. Zhang, B. Liu, Nat. Energy 2018, $3,140$.

[21] I. V. Lightcap, T. H. Kosel, P. V. Kamat, Nano Lett. 2010, 10, 577.
[22] a) H. B. Yang, S. F. Hung, S. Liu, K. Yuan, S. Miao, L. Zhang, X. Huang, H. Y. Wang, W. Cai, R. Chen, Nat. Energy 2018, 3, 140; b) W. Bi, X. Li, R. You, M. Chen, R. Yuan, W. Huang, X. Wu, W. Chu, C. Wu, Y. Xie, Adv. Mater. 2018, 30, 1706617.

[23] a) W. Liu, L. Zhang, W. Yan, X. Liu, X. Yang, S. Miao, W. Wang, A. Wang, T. Zhang, Chem. Sci. 2016, 7, 5758; b) Y. Pan, R. Lin, Y. Chen, S. Liu, W. Zhu, X. Cao, W. Chen, K. Wu, W. C. Cheong, Y. Wang, J. Am. Chem. Soc. 2018, 140, 4218.

[24] J. v. Liebig, Ann. Pharm. 1834, 10, 10.

[25] a) M. Groenewolt, M. Antonietti, Adv. Mater. 2005, 17, 1789; b) T. Komatsu, T. Nakamura, J. Mater. Chem. 2001, 11, 474; c) X. Li, J. Zhang, L. Shen, Y. Ma, W. Lei, Q. Cui, G. Zou, Appl. Phys. A 2009, 94, 387; d) Y. Wang, Y. Di, M. Antonietti, H. Li, X. Chen, X. Wang, Chem. Mater. 2010, 22, 5119.

[26] A. Thomas, A. Fischer, F. Goettmann, M. Antonietti, J. O. Müller, R. Schlögl, J. M. Carlsson, J. Mater. Chem. 2008, 18, 4893.

[27] X. Wang, K. Maeda, A. Thomas, K. Takanabe, G. Xin, J. M. Carlsson, K. Domen, M. Antonietti, Nat. Mater. 2009, 8, 76.

[28] Y. D. Hou, A. B. Laursen, J. S. Zhang, G. G. Zhang, Y. S. Zhu, X. C. Wang, S. Dahl, I. Chorkendorff, Angew. Chem., Int. Ed. 2013, 52, 3621.

[29] S. Nayak, L. Mohapatra, K. Parida, J. Mater. Chem. A 2015, 3, 18622.

[30] a) Y. Plotnik, M. C. Rechtsman, D. Song, M. Heinrich, J. M. Zeuner, S. Nolte, Y. Lumer, N. Malkova, J. Xu, A. Szameit, Nat. Mater. 2014, 13, 57; b) S. Manzeli, D. Ovchinnikov, D. Pasquier, O. V. Yazyev, A. Kis, Nat. Rev. Mater. 2017, 2, 17033; c) F. M. Wang, T. A. Shifa, X. Y. Zhan, Y. Huang, K. L. Liu, Z. Z. Cheng, C. Jiang, J. He, Nanoscale 2015, 7, 19764; d) J. Nilsson, A. C. Neto, F. Guinea, N. Peres, Phys. Rev. Lett. 2006, 97, 266801; e) X. Chia, A. Y. S. Eng, A. Ambrosi, S. M. Tan, M. Pumera, Chem. Rev. 2015, 115, 11941.

[31] M. Chhowalla, H. S. Shin, G. Eda, L. J. Li, K. P. Loh, H. Zhang, Nat. Chem. 2013, 5, 263.

[32] G. W. Shim, W. Hong, S. Y. Yang, S. Y. Choi, J. Mater. Chem. A 2017, 5, 14950.

[33] a) H. Tributsch, Ber. Bunsen-Ges. Phys. Chem. 1977, 81, 361; b) M. Pumera, Z. Sofer, A. Ambrosi, J. Mater. Chem. A 2014, 2, 8981.

[34] a) T. F. Jaramillo, K. P. Jørgensen, J. Bonde, J. H. Nielsen, S. Horch, I. Chorkendorff, Science 2007, 317, 100; b) J. Kibsgaard, Z. Chen, B. N. Reinecke, T. F. Jaramillo, Nat. Mater. 2012, 11, 963; c) M. R. Gao, Y. F. Xu, J. Jiang, S. H. Yu, Chem. Soc. Rev. 2013, 42, 2986.

[35] M. Naguib, V. N. Mochalin, M. W. Barsoum, Y. Gogotsi, Adv. Mater. 2014, 26, 992.

[36] Q. Wang, D. O'Hare, Chem. Rev. 2012, 112, 4124.

[37] S. Zhao, Y. Wang, J. Dong, C. T. He, H. Yin, P. An, K. Zhao, X. Zhang, C. Gao, L. Zhang, J. Lv, J. Wang, J. Zhang, A. M. Khattak, N. A. Khan, Z. Wei, J. Zhang, S. Liu, H. Zhao, Z. Tang, Nat. Energy 2016, 1, 16184.

[38] H. Wang, Y. Wu, X. Yuan, G. Zeng, J. Zhou, X. Wang, J. W. Chew, Adv. Mater. 2018, 30, 1704561.

[39] Z. W. Seh, K. D. Fredrickson, B. Anasori, J. Kibsgaard, A. L. Strickler, M. R. Lukatskaya, Y. Gogotsi, T. F. Jaramillo, A. Vojvodic, ACS Energy Lett. 2016, 1, 589.

[40] R. Roldán, L. Chirolli, E. Prada, J. A. Silva-Guillén, P. San-Jose, F. Guinea, Chem. Soc. Rev. 2017, 46, 4387.

[41] B. Song, S. Jin, Joule 2017, 1, 220.

[42] X. H. Li, M. Antonietti, Chem. Soc. Rev. 2013, 42, 6593.

[43] C. Tan, J. Chen, X. J. Wu, H. Zhang, Nat. Rev. Mater. 2018, 3, 17089.

[44] K. Novoselov, A. Mishchenko, A. Carvalho, A. C. Neto, Science 2016, 353, aac9439.

[45] a) H. Wang, F. Liu, W. Fu, Z. Fang, W. Zhou, Z. Liu, Nanoscale 2014, 6, 12250; b) Y. Gong, J. Lin, X. Wang, G. Shi, S. Lei, Z. Lin, X. Zou, G. Ye, R. Vajtai, B. I. Yakobson, Nat. Mater. 2014, 13, 1135; c) Y. Yoo, Z. P. Degregorio, J. E. Johns, J. Am. Chem. Soc. 2015, $137,14281$. 
[46] a) Z. Cai, B. Liu, X. Zou, H. M. Cheng, Chem. Rev. 2018, 118, 6091; b) X. Duan, C. Wang, J. C. Shaw, R. Cheng, Y. Chen, H. Li, X. Wu, Y. Tang, Q. Zhang, A. Pan, Nat. Nanotechnol. 2014, 9, 1024 c) F. Wang, Z. Wang, T. A. Shifa, Y. Wen, F. Wang, X. Zhan, Q. Wang, K. Xu, Y. Huang, L. Yin, Adv. Funct. Mater. 2017, 27, 1603254; d) Q. Wang, M. Safdar, Z. Wang, J. He, Adv. Mater. 2013, 25, 3915.

[47] C. R. Woods, L. Britnell, A. Eckmann, R. S. Ma, J. C. Lu, H. M. Guo, X. Lin, G. L. Yu, Y. Cao, R. V. Gorbachev, A. V. Kretinin, J. Park, L. A. Ponomarenko, M. I. Katsnelson, Y. N. Gornostyrev, K. Watanabe, T. Taniguchi, C. Casiraghi, H. J. Gao, A. K. Geim, K. S. Novoselov, Nat. Phys. 2014, 10, 451.

[48] B. Xu, T. L. Feng, M. T. Agne, Q. Tan, Z. Li, K. Imasato, L. Zhou, J. H. Bahk, X. L. Ruan, G. J. Snyder, Y. Wu, Angew. Chem., Int. Ed. 2018, 57, 2413

[49] S. Xie, L. Tu, Y. Han, L. Huang, K. Kang, K. U. Lao, P. Poddar, C. Park, D. A. Muller, R. A. DiStasio, J. Park, Science 2018, 359, 1131.

[50] a) W. Dang, H. Peng, H. Li, P. Wang, Z. Liu, Nano Lett. 2010, 10, 2870; b) M. Lin, D. Wu, Y. Zhou, W. Huang, W. Jiang, W. Zheng, S. Zhao, C. Jin, Y. Guo, H. Peng, Z. Liu, J. Am. Chem. Soc. 2013 135,13274

[51] Y. Shi, W. Zhou, A. Y. Lu, W. Fang, Y. H. Lee, A. L. Hsu, S. M. Kim, K. K. Kim, H. Y. Yang, L. J. Li, J. C. Idrobo, J. Kong, Nano Lett. 2012 12, 2784.

[52] a) J. P. Shi, M. X. Liu, J. X. Wen, X. B. Ren, X. B. Zhou, Q. Q. Ji, D. L. Ma, Z. Yu, C. H. Jin, H. J. Chen, S. Z. Deng, N. S. Xu, Z. F. Liu, Y. F. Zhang, Adv. Mater. 2015, 27, 7086; b) H. Li, J. B. Wu, F. Ran, M. L. Lin, X. L. Liu, Y. Zhao, X. Lu, Q. Xiong, J. Zhang, W. Huang, H. Zhang, P. H. Tan, ACS Nano 2017, 11, 11714.

[53] C. Xu, S. Song, Z. Liu, L. Chen, L. Wang, D. Fan, N. Kang, X. Ma, H. M. Cheng, W. Ren, ACS Nano 2017, 11, 5906.

[54] J. P. Shi, R Tong, X. B. Zhou, Y. Gong, Z. P. Zhang, Q. Q. Ji, Y. Zhang, Q. Y. Fang, L. Gu, X. N. Wang, Z. F. Liu, Y. F. Zhang, Adv. Mater. 2016, 28, 10664.

[55] a) J. M. Woods, Y. Jung, Y. Xie, W. Liu, Y. Liu, H. Wang, J. J. Cha, ACS Nano 2016, 10, 2004; b) Y. M. He, A. Sobhani, S. D. Lei, Z. H. Zhang, Y. J. Gong, Z. H. Jin, W. Zhou, Y. C. Yang, Y. Zhang, X. F. Wang, B. Yakobson, R. Vajtai, N. J. Halas, B. Li, E. Q. Xie, P. Ajayan, Adv. Mater. 2016, 28, 5126.

[56] a) Y. Liu, N. O. Weiss, X. Duan, H. C. Cheng, Y. Huang, X. Duan, Nat. Rev. Mater. 2016, 1, 16042; b) L. Zhang, K. Liu, A. B. Wong, J. Kim, X. Hong, C. Liu, T. Cao, S. G. Louie, F. Wang, P. Yang, Nano Lett. 2014, 14, 6418; c) K. S. Novoselov, A. Mishchenko, A. Carvalho, A. H. Castro Neto, Science 2016, 353.

[57] C. Wang, Q. He, U. Halim, Y. Liu, E. Zhu, Z. Lin, H. Xiao, X. Duan, Z. Feng, R. Cheng, N. O. Weiss, G. Ye, Y. C. Huang, H. Wu, H. C. Cheng, I. Shakir, L. Liao, X. Chen, W. A. Goddard lii, Y. Huang, X. Duan, Nature 2018, 555, 231.

[58] X. Cai, T. C. Ozawa, A. Funatsu, R. Ma, Y. Ebina, T. Sasaki, J. Am Chem. Soc. 2015, 137, 2844

[59] H. Fang, C. Battaglia, C. Carraro, S. Nemsak, B. Ozdol, J. S. Kang, H. A. Bechtel, S. B. Desai, F. Kronast, A. A. Unal, G. Conti, C. Conlon, G. K. Palsson, M. C. Martin, A. M. Minor, C. S. Fadley E. Yablonovitch, R. Maboudian, A. Javey, Proc. Natl. Acad. Sci. USA 2014, 111, 6198

[60] A. K. Geim, I. V. Grigorieva, Nature 2013, 499, 419.

[61] F. M. Wang, P. He, Y. C. Li, T. A. Shifa, Y. Deng, K. L. Liu, Q. S. Wang, F. Wang, Y. Wen, Z. X. Wang, X. Y. Zhan, L. F. Sun, J. He, Adv. Funct. Mater. 2017, 27, 1605802.

[62] Y. Li, H. Wang, L. Xie, Y. Liang, G. Hong, H. Dai, J. Am. Chem. Soc. 2011, 133, 7296.

[63] T. A. Shifa, F. M. Wang, Z. Z. Cheng, X. Y. Zhan, Z. X. Wang, K. L. Liu, M. Safdar, L. F. Sun, J. He, Nanoscale 2015, 7, 14760.

[64] Y. Lei, S. Pakhira, K. Fujisawa, X. Wang, O. O. lyiola, N. Perea López, A. Laura Elías, L. Pulickal Rajukumar, C. Zhou, B. Kabius,
N. Alem, M. Endo, R. Lv, J. L. Mendoza-Cortes, M. Terrones, ACS Nano 2017, 11, 5103

[65] J. Kang, J. Li, S. S. Li, J. B. Xia, L. W. Wang, Nano Lett. 2013, 13, 5485 .

[66] a) S. J. Haigh, A. Gholinia, R. Jalil, S. Romani, L. Britnell, D. C. Elias, K. S. Novoselov, L. A. Ponomarenko, A. K. Geim, R. Gorbachev, Nat. Mater. 2012, 11, 764; b) C. Zhang, C. P. Chuu, X. Ren, M. Y. Li, L. J. Li, C. Jin, M. Y. Chou, C. K. Shih, Sci. Adv. 2017, 3, el601459; c) M. Gobbi, S. Bonacchi, J. X. Lian, Y. Liu, X. Y. Wang, M. A. Stoeckel, M. A. Squillaci, G. D'Avino, A. Narita, K. Müllen, X. Feng, Y. Olivier, D. Beljonne, P. Samorì, E. Orgiu, Nat. Commun. 2017, 8, 14767

[67] W. Che, W. Cheng, T. Yao, F. Tang, W. Liu, H. Su, Y. Huang, Q. Liu, J. Liu, F. Hu, Z. Pan, Z. Sun, S. Wei, J. Am. Chem. Soc. 2017, 139, 3021.

[68] J. Zhang, T. Wang, D. Pohl, B. Rellinghaus, R. Dong, S. Liu, X. Zhuang, X. Feng, Angew. Chem., Int. Ed. 2016, 55, 6702.

[69] V. O. Özçelik, J. G. Azadani, C. Yang, S. J. Koester, T. Low, Phys. Rev. B 2016, 94, 035125.

[70] a) S. Memaran, N. R. Pradhan, Z. Lu, D. Rhodes, J. Ludwig, Q. Zhou, O. Ogunsolu, P. M. Ajayan, D. Smirnov, A. I. Fernández-Domínguez, F. J. García-Vidal, L. Balicas, Nano Lett. 2015, 15, 7532; b) M. Long, E. Liu, P. Wang, A. Gao, H. Xia, W. Luo, B. Wang, J. Zeng, Y. Fu, K. Xu, W. Zhou, Y. Lv, S. Yao, M. Lu, Y. Chen, Z. Ni, Y. You, X. Zhang, S. Qin, Y. Shi, W. Hu, D. Xing, F. Miao, Nano Lett. 2016, 16, 2254.

[71] a) C. H. Liu, G. Clark, T. Fryett, S. Wu, J. Zheng, F. Hatami, X. Xu, A. Majumdar, Nano Lett. 2017, 17, 200; b) A. Levi, T. Chiu, Appl. Phys. Lett. 1987, 51, 984; c) F. Capasso, S. Sen, A. C. Gossard, A. L. Hutchinson, J. H. English, IEEE Electron Device Lett. 1986, 7, 573; d) K. Roy, M. Padmanabhan, S. Goswami, T. P. Sai, G. Ramalingam, S. Raghavan, A. Ghosh, Nat. Nanotechnol. 2013, 8, 826; e) P. Rivera, J. R. Schaibley, A. M. Jones, J. S. Ross, S. Wu, G. Aivazian, P. Klement, K. Seyler, G. Clark, N. J. Ghimire, J. Yan, D. G. Mandrus, W. Yao, X. Xu, Nat. Commun. 2015, 6, 6242.

[72] a) H. Li, C. Tsai, A. L. Koh, L. Cai, A. W. Contryman, A. H. Fragapane, J. Zhao, H. S. Han, H. C. Manoharan, F. Abild-Pedersen, J. K. Nørskov, X. Zheng, Nat. Mater. 2015, 15, 48; b) D. Voiry, R. Fullon, J. Yang, C. de Carvalho Castro e Silva, R. Kappera, I. Bozkurt, D. Kaplan, M. J. Lagos, P. E. Batson, G. Gupta, A. D. Mohite, L. Dong, D. Er, V. B. Shenoy, T. Asefa, M. Chhowalla, Nat. Mater. 2016, 15, 1003.

[73] a) Y. Liang, Y. Li, H. Wang, J. Zhou, J. Wang, T. Regier, H. Dai, Nat. Mater. 2011, 10, 780; b) J. Yang, D. Voiry, S. J. Ahn, D. Kang, A. Y. Kim, M. Chhowalla, H. S. Shin, Angew. Chem., Int. Ed. 2013 , 52,13751

[74] D. C. Geng, X. X. Zhao, Z. X. Chen, W. W. Sun, W. Fu, J. Y. Chen, W. Liu, W. Zhou, K. P. Loh, Adv. Mater. 2017, 29, 1700072.

[75] N. T. Suen, S. F. Hung, Q. Quan, N. Zhang, Y. J. Xu, H. M. Chen, Chem. Soc. Rev. 2017, 46, 337.

[76] J. H. Wang, D. N. Liu, H. Huang, N. Yang, B. Yu, M. Wen, X. Wang, P. K. Chu, X. F. Yu, Angew. Chem., Int. Ed. 2018, 57, 2600.

[77] Y. Fan, S. Ida, A. Staykov, T. Akbay, H. Hagiwara, J. Matsuda, K. Kaneko, T. Ishihara, Small 2017, 13, 1700099.

[78] Y. J. Wang, Q. S. Wang, X. Y. Zhan, F. M. Wang, M. Safdar, J. He, Nanoscale 2013, 5, 8326.

[79] M. G. Walter, E. L. Warren, J. R. McKone, S. W. Boettcher, Q. Mi, E. A. Santori, N. S. Lewis, Chem. Rev. 2010, 110, 6446.

[80] A. Fujishima, K. Honda, Nature 1972, 238, 37.

[81] Q. Xiang, J. Yu, M. Jaroniec, J. Am. Chem. Soc. 2012, 134, 6575.

[82] M. Wang, P. Ju, J. Li, Y. Zhao, X. Han, Z. Hao, ACS Sustainable Chem. Eng. 2017, 5, 7878.

[83] a) Y. Zhou, L. Zhang, W. Huang, Q. Kong, X. Fan, M. Wang, J. Shi, Carbon 2016, 99, 111; b) S. Bhattacharyya, M. Lübbe, F. Richter, J. Appl. Phys. 2000, 88, 5043. 
[84] J. Ran, W. Guo, H. Wang, B. Zhu, J. Yu, S. Z. Qiao, Adv. Mater. 2018, 30, 1800128 .

[85] a) C. Hahn, T. Hatsukade, Y. G. Kim, A. Vailionis, J. H. Baricuatro, D. C. Higgins, S. A. Nitopi, M. P. Soriaga, T. F. Jaramillo, Proc. Natl. Acad. Sci. USA 2017, 114, 5918; b) Z. Lei, Z. Zhi Jian, G. Jinlong, Angew. Chem., Int. Ed. 2017, 56, 11326.

[86] a) J. Low, J. Yu, W. Ho, J. Phys. Chem. Lett. 2015, 6, 4244; b) P. Q. Wang, Y. Bai, P. Y. Luo, J. Y. Liu, Catal. Commun. 2013, 38, 82; c) T. S. Wu, L. Y. Zou, D. X. Han, F. H. Li, Q. X. Zhang, L. Niu, Green Chem. 2014, 16, 2142.

[87] J. G. Yu, J. Jin, B. Cheng, M. Jaroniec, J. Mater. Chem. A 2014, 2, 3407.

[88] W. J. Ong, L. L. Tan, S. P. Chai, S. T. Yong, A. R. Mohamed, Nano Energy 2015, 13, 757

[89] a) T. Di, B. Zhu, B. Cheng, J. Yu, J. Xu, J. Catal. 2017, 352, 532; b) B. Zhu, P. Xia, Y. Li, W. Ho, J. Yu, Appl. Surf. Sci. 2017, 391, 175.

[90] Z. Jiang, W. Wan, H. Li, S. Yuan, H. Zhao, K. Wong Po, Adv. Mater. 2018, 30, 1706108.

[91] a) K. P. Loh, Q. Bao, G. Eda, M. Chhowalla, Nat. Chem. 2010, 2, 1015; b) K. Krishnamoorthy, R. Mohan, S. J. Kim, Appl. Phys. Lett. 2011, 98, 244101; c) C. Su, M. Acik, K. Takai, J. Lu, S. j. Hao, Y. Zheng, P. Wu, Q. Bao, T. Enoki, Y. J. Chabal, K. Ping Loh, Nat. Commun. 2012, 3, 1298; d) Y. Te Fu, S. Jhih-Ming, C. Ching, C. Ting-Hsiang, T. Hsisheng, Adv. Funct. Mater. 2010, 20, 2255.

[92] a) Y. Hori, A. Murata, R. Takahashi, J. Chem. Soc., Faraday Trans. 1 1989, 85, 2309; b) Y. Hori, R. Takahashi, Y. Yoshinami, A. Murata, J. Phys. Chem. B 1997, 101, 7075.

[93] I. Shown, H. C. Hsu, Y. C. Chang, C. H. Lin, P. K. Roy, A. Ganguly, C. H. Wang, J. K. Chang, C. I. Wu, L. C. Chen, K. H. Chen, Nano Lett. 2014, 14, 6097.

[94] a) A. W. Robertson, B. Montanari, K. He, J. Kim, C. S. Allen, Y. A. Wu, J. Olivier, J. Neethling, N. Harrison, A. I. Kirkland, J. H. Warner, Nano Lett. 2013, 13, 1468; b) T. Tong, B. Zhu, C. Jiang, B. Cheng, J. Yu, Appl. Surf. Sci. 2018, 433, 1175.

[95] K. Jiang, S. Siahrostami, T. T. Zheng, Y. F. Hu, S. Hwang, E. Stavitski, Y. D. Peng, J. Dynes, M. Gangisetty, D. Su, K. Attenkofer, H. T. Wang, Energy Environ. Sci. 2018, 11, 893.

[96] G. Chao, C. Shuangming, W. Ying, W. Jiawen, Z. Xusheng, Z. Junfa, S. Li, Z. Wenkai, X. Yujie, Adv. Mater. 2018, 30, 1803181.

[97] D. Voiry, H. S. Shin, K. P. Loh, M. Chhowalla, Nat. Rev. Chem. 2018, 2, 0105

[98] X. Han, X. Tong, X. Liu, A. Chen, X. Wen, N. Yang, X. Y. Guo, ACS Catal. 2018, 8, 1828.

[99] L. Liao, J. Zhu, X. J. Bian, L. N. Zhu, M. D. Scanlon, H. H. Girault, B. H. Liu, Adv. Funct. Mater. 2013, 23, 5326.
[100] X. Zheng, J. Xu, K. Yan, H. Wang, Z. Wang, S. Yang, Chem. Mater. 2014, 26, 2344.

[101] Y. Xuying, Y. Ya, M. Mao, Z. Ke, L. Pingwei, Y. Junhe, Z. Bin, X. B. Yu, Chem. - Eur. J. 2018, 24, 556.

[102] S. Chen, J. Duan, Y. Tang, B. Jin, S. Zhang Qiao, Nano Energy 2015, $11,11$.

[103] F. Li, L. Zhang, J. Li, X. Q. Lin, X. Z. Li, Y. Y. Fang, J. W. Huang, W. Z. Li, M. Tian, J. Jin, R. Li, J. Power Sources 2015, 292, 15.

[104] Y. Yan, X. M. Ge, Z. L. Liu, J. Y. Wang, J. M. Lee, X. Wang, Nanoscale 2013, 5, 7768.

[105] D. J. Li, U. N. Maiti, J. Lim, D. S. Choi, W. J. Lee, Y. Oh, G. Y. Lee, S. O. Kim, Nano Lett. 2014, 14, 1228.

[106] L. Yang, W. Zhou, J. Lu, D. Hou, Y. Ke, G. Li, Z. Tang, X. Kang, S. Chen, Nano Energy 2016, 22, 490.

[107] C. Dahl-Petersen, M. Šarić, M. Brorson, P. G. Moses, J. Rossmeisl, J. V. Lauritsen, S. Helveg, ACS Nano 2018, 12, 5351.

[108] C. Xiaoshuang, L. Guangbo, Z. Wei, F. Wei, C. Wenwu, H. Wenping, H. PingAn, Adv. Funct. Mater. 2016, 26, 8537.

[109] Z. Guan, P. Wang, Q. Li, G. Li, J. Yang, Dalton Trans. 2018, 47, 6800 .

[110] Z. Zhang, K. Liu, Z. Feng, Y. Bao, B. Dong, Sci. Rep. 2016, 6, 19221.

[111] L. Yang, Y. L. Lv, D. P. Cao, J. Mater. Chem. A 2018, 6, 3926.

[112] X. Kuang, Y. Luo, R. Kuang, Z. Wang, X. Sun, Y. Zhang, Q. Wei, Carbon 2018, 137, 433.

[113] J. Wu, Z. Ren, S. Du, L. Kong, B. Liu, W. Xi, J. Zhu, H. Fu, Nano Res. 2016, 9, 713.

[114] S. Xue, L. Chen, Z. Liu, H. M. Cheng, W. Ren, ACS Nano 2018, 12, 5297.

[115] M. Yu, S. Zhou, Z. Wang, J. Zhao, J. Qiu, Nano Energy 2018, 44, 181.

[116] F. Wang, T. A. Shifa, P. He, Z. Cheng, J. Chu, Y. Liu, Z. Wang, F. Wang, Y. Wen, L. Liang, J. He, Nano Energy 2017, 40, 673.

[117] Y. Zhang, J. Du, Z. Wang, M. Luo, Y. Tian, T. Fujita, Q. Xue, M. Chen, ACS Appl. Energy Mater. 2018, 1, 2183.

[118] M. Wang, P. Ju, Y. Zhao, J. J. Li, X. X. Han, Z. M. Hao, New J. Chem. 2018, 42, 910.

[119] J. Zhang, J. Yu, M. Jaroniec, J. R. Gong, Nano Lett. 2012, 12, 4584.

[120] Y. J. Zou, J. W. Shi, D. D. Ma, Z. Y. Fan, L. H. Cheng, D. K. Sun, Z. Y. Wang, C. M. Niu, ChemSusChem 2018, 11, 1187.

[121] R. Jingrun, G. Weiwei, W. Hailong, Z. Bicheng, Y. Jiaguo, Q. Shi-Zhang, Adv. Mater. 2018, 30, 1800128.

[122] S. Tonda, S. Kumar, M. Bhardwaj, P. Yadav, S. Ogale, ACS Appl. Mater. Interfaces 2018, 10, 2667.

[123] H. Jung, K. M. Cho, K. H. Kim, H. W. Yoo, A. Al-Saggaf, I. Gereige, H. T. Jung, ACS Sustainable Chem. Eng. 2018, 6, 5718. 